\title{
- Contrasting Cloud Regimes and Associated Rainfall over the South Asian and East Asian Monsoon Regions
}

\author{
RUOTING Wu ${ }^{\mathrm{a}, \mathrm{b}}$ AND GUIXING CHEN ${ }^{\mathrm{a}, \mathrm{b}}$ \\ ${ }^{a}$ School of Atmospheric Sciences and Guangdong Province Key Laboratory for Climate Change and Natural Disaster Studies, \\ Sun Yat-sen University, Guangzhou, China \\ b Southern Marine Science and Engineering Guangdong Laboratory (Zhuhai), Zhuhai, China
}

(Manuscript received 21 December 2020, in final form 27 January 2021)

\begin{abstract}
The Asian monsoon has large spatial and temporal variabilities in winds and precipitation. This study reveals that the Asian monsoon also exhibits pronounced regional differences in cloud regimes and cloud-rainfall relationship at a wide range of time scales from diurnal to seasonal to interannual. Over South (East) Asia, the convectively active regime of deep convection (CD) occurs frequently in June-September (March-September) with a late-afternoon peak (morning feature). The intermediate mixture (IM) regime over South Asia mainly occurs in summer and maximizes near noon. It develops as $\mathrm{CD}$ at late afternoon and dissipates as convective cirrus (CC) after midnight, showing a life cycle of thermal convection in response to solar radiation. Over East Asia, IM is dominant in cold seasons with a small diurnal cycle, indicating a prevalence of midlevel stratiform clouds. Further analyses show that CD and CC contribute $80 \%-90 \%$ of the rainfall amount and most of the intense rainfall in the two key regions. The CD-related rainfall also accounts for the pronounced diurnal cycles of summer rainfall with a late-afternoon peak (morning feature) over northern India (Southeast China). The afternoon CD-related rainfall mainly results from thermal convection under the moderate humidity but warm conditions particularly over northern India, while the morning CD-related rainfall over Southeast China is more related to the processes with high humidity. The $\mathrm{CD} / \mathrm{CC}$ related rainfall also exhibits large interannual variations that explain $\sim 90 \%$ of the interannual variance of summer rainfall. The interannual variations of $\mathrm{CD} / \mathrm{CC}$ occurrence are positively correlated with the moist southerlies and induced convergence, especially over Southeast China, suggesting a close relationship between cloud regimes and monsoon activities.
\end{abstract}

KEYWORDS: Clouds; Monsoons; Precipitation; Diurnal effects; Interannual variability; Seasonal cycle

\section{Introduction}

The monsoon systems dominate the weather and climate over Asia with a profound influence on half of the global population. It is recognized that the Asian monsoon exhibits a wide range of variabilities from diurnal to seasonal to interannual time scales (e.g., Ding 1992; Lau and Nath 2000; Goswami and Mohan 2001; Romatschke et al. 2010; Li et al. 2016; Fujinami et al. 2017; Chen 2020). The onset of the Asian summer monsoon is accompanied by the seasonal change of atmospheric circulations and rainfall amount (e.g., Ding 1992; Matsumoto 1997; Sahai et al. 2000; Wang and LinHo 2002; Ding and Chan 2005). Meanwhile, the diurnal variations of winds and precipitation become pronounced in summer as a response to regional forcings (e.g., Ohsawa et al. 2001; Hirose and Nakamura 2005; Basu 2007; Yu et al. 2007; Chen et al. 2009a,b; G. Chen et al. 2013; Xue et al. 2018; P. Li et al. 2020). The monsoon systems also exhibit large interannual variations because of the large-scale external forcings such as ENSO (Tian and Yasunari 1992; Zhang et al. 1996; Kripalani and Kulkarni 1997; Lau and Nath 2000; Wang et al. 2001). The variabilities of summer monsoon show pronounced regional differences over South Asia and East Asia because of different terrains and atmospheric

\footnotetext{
๑ Denotes content that is immediately available upon publication as open access.
}

Corresponding author: Guixing Chen, chenguixing@mail.sysu. edu.cn conditions (e.g., Wang and LinHo 2002; Ding 2007; Chen 2020). Improved understanding of the complicated spatiotemporal properties of Asian monsoon is a key scientific issue for a better prediction of weather and regional/global climate.

Clouds play a key role in the energy and hydrological cycles of the Earth-atmosphere system (e.g., Hartmann and Larson 2002; Stephens 2005; Furtado et al. 2016). The studies of clouds are also essential for understanding the weather/climate in the monsoon regions. One of the key aspects includes the diurnal, seasonal, and interannual variations of cloud properties such as cloud fraction and cloud-top pressure, and their regional differences in the Asian monsoon regions (e.g., Luo et al. 2009; Chen et al. 2012; Wang and Wang 2016; Zhao et al. 2019; J. Li et al. 2019, 2020; Yang et al. 2020). The different cloud properties along with other factors such as aerosols certainly lead to robust differences of cloud radiative forcing and thus affect regional weather and climate (J. Li et al. 2009, 2017; Z. Li et al. 2019). However, it is difficult to define the dominance of a specific cloud type because many types of clouds can jointly occur in a given region. To address this issue, Jakob and Tselioudis (2003) first proposed to categorize the joint frequency maps of cloud-top pressure and optical thickness into several major modes using cluster analysis. Each mode in the height-thickness diagram consists of a group of various clouds that tend to occur together. These so-called cloud regimes (or weather states) are mostly used in the tropics since they provide useful information to identify distinct convection and large-scale state of the tropical atmosphere (Rossow et al. 2005; Tan et al. 2013). For instance, the tropical cloud regimes 
are found to exhibit multiscale variabilities that are closely associated with the MJO, annual cycle, and ENSO events (e.g., Rossow et al. 2005; Tromeur and Rossow 2010; Stachnik et al. 2013). Tselioudis and Rossow (2011) found that the cloud regimes in most tropical regions are dominated by annual cycle whereas those in the eastern Indian and westerncentral Pacific are regulated by El Niño frequencies. These research studies mainly focused on the cloud regimes in the tropics at daily/monthly mean or longer time scales. A few recent studies began to examine the diurnal variation of cloud regimes in the Maritime Continent using the newly derived infrared dataset of cloud regimes (Worku et al. 2019, 2020). The cloud regimes may provide an interesting insight to study the multiscale variabilities of Asian monsoon that varies in different regions.

Cloud-based cloud regimes are also analyzed in conjunction with precipitation data to describe the hydrological cycle and its relation to clouds in the tropics. The cloud regimes have different precipitation rates (Tromeur and Rossow 2010; Rossow et al. 2013; Tan et al. 2013) and are closely associated with different precipitation regimes (Jakob and Schumacher 2008; Luo et al. 2017). The most convectively active regime, despite a low occurrence, is found to contribute nearly half of the precipitation in the tropics (Lee et al. 2013). Meanwhile, its change in the occurrence frequency is shown to strongly explain the increase of tropical precipitation in the warming climate (Tan et al. 2015). These studies have emphasized the importance of cloud regimes in the hydrological cycle in the tropics, but the relationship of cloud regimes and precipitation systems in the Asian monsoon areas with evident regionality is still less well understood. We expect that the combination of cloud regimes and precipitation data helps us to objectively identify prevalent cloud regimes that result in rainfall in the Asian monsoon regions.

The cloud regimes also play a key role in bridging the gap between atmospheric conditions and precipitation systems, which is a key issue for studying cloud-precipitation interactions. Previous studies have shown that the cloud regimes can be linked to various atmospheric conditions such as humidity, vertical motion, stability, and thermodynamic properties (Jakob et al. 2005; Stachnik et al. 2013; Tan et al. 2013; Handlos and Back 2014). They also showed that the atmospheric conditions of different cloud regimes are distinguishable from each other. The cloud regimes thus provide us a viable framework to describe the variations of weather and climate, because the complex interaction of a large number of atmospheric variables with cloud processes can be simplified into several recurring cloud patterns (Rossow et al. 2005). These studies mainly focus on the linkage between atmospheric conditions and cloud regimes in a climate-mean manner in the tropics. So far, it is unclear how the cloud-precipitation relation works in Asian monsoon regions, where atmospheric conditions are largely affected by monsoon activities and have complex variabilities (e.g., Sun et al. 2011; Radhakrishna et al. 2019).

The purpose of this study is to examine the variabilities of cloud regimes and to further clarify their relationship to monsoon activities (precipitation and atmospheric conditions) at a wide range of time scales. Of particular interest is the diurnal scale that previous studies paid less attention to. We pay more attention to the regional differences over northern India and Southeast China, the key land regions of the South Asian and East Asian monsoon systems. The rest of this paper is organized as follows. The data and methods are introduced in section 2. In section 3, we examine the spatial distribution, seasonal variation, diurnal variation, and regional features of cloud regimes. In section 4, we estimate the relationship between cloud regimes and precipitation with emphasis on diurnal and seasonal variations. We also illustrate how the rainfall of cloud regimes varies with atmospheric humidity. In section 5, we further examine the interannual variability of cloud regimes and precipitation in association with the longterm variations of monsoon activities. Finally, conclusions and discussion are given in section 6 .

\section{Data and methods}

The International Satellite Cloud Climatology Project (ISCCP) provides ready-made cloud regime products. The detailed method to obtain cloud regime products is described in Jakob and Tselioudis (2003) and briefly as follows. The ISCCP D1 dataset provided the frequency-distribution histograms of cloud-top pressure and optical thickness with a spatial resolution of $280 \mathrm{~km} \times 280 \mathrm{~km}$ and 3-h intervals. Each histogram has been calculated by the satellite pixels of cloudtop pressure and optical thickness at a high resolution of kilometers. The histogram thus represents the occurrence frequency of various cloud types in the $280 \mathrm{~km} \times 280 \mathrm{~km}$ domain. Then, eight centroids (cloud regimes) are obtained using cluster analysis on a huge number of joint histograms in the tropics and subtropics $\left(35^{\circ} \mathrm{S}-35^{\circ} \mathrm{N}\right)$. The Euclidean distance between each histogram and the centroids was calculated so that each histogram was allocated to the cloud regimes with the shortest distance. Previous studies have shown that the identification of these eight kinds of cloud regimes is robust (Mekonnen and Rossow 2011; Oreopoulos and Rossow 2011; Tan et al. 2013).

Tan et al. (2013) have shown that cloud regimes are useful indicators of the typical states of the tropical atmosphere ranging from convectively active to convectively suppressed conditions. The first cloud regime associated with convectively deep convection (CD) has the highest occurrence frequency of high-top and optically thick clouds. The second cloud regime is convectively cirrus (CC), which also represents the convective conditions with thick cirrus rather than thin cirrus in the studies of cloud regimes. Nevertheless, CC has an optical thickness slightly smaller than $\mathrm{CD}$, and thus it mainly corresponds to the dissipating convection (e.g., Lee et al. 2013; Tan et al. 2013). The third regime, intermediate mixture (IM), is dominated by the clouds with medium cloud-top height and thickness. The IM also has some convective clouds, denoting intermediate or moderate convection. Another intermediate regime is dominated by very thin and high-top cirrus (IC), but it should be cautioned that the thin cirrus might be an artifact due to the adjustment of ISCCP data processing (Marchand et al. 2010; Tan et al.2013). The other four regimes are named ST, SS1, SS2, and SS3, reflecting the convectively suppressed situations because they are dominated by lowlevel clouds. ST has the lowest cloud cover and mainly 
features shallow cumulus, while the other three regimes are dominated by stratocumulus.

The cloud regimes can be obtained originally only in the daytime because visible light records are required for the retrieval of optical thickness. To derive the cloud regimes in the nighttime, Tan and Jakob (2013) estimated the cloud-top pressure profiles of the original eight cloud regimes and obtained seven IR-only regimes. They removed the IC regime because it was not well behaved. To examine the uncertainties of IR-only data, we calculated the match degree between IR-only regimes and original VIS-IR regimes as in Tan and Jakob (2013). Figure 1 shows matrix plots of how the IR-only regimes match the original regimes over northern India and Southeast China, the two key regions in this study. It shows that the highest match degrees are on the diagonal; in particular, the CD has an exact match of $\sim 80 \%$ and $\sim 89 \%$ for ST over northern India (Fig. 1a). For the cases when the IR-only regimes do not give an extract match, they mostly report the neighboring regimes, indicating the bias is somewhat limited. This suggests a fairly good consistency between the two datasets, which is comparable to the performance in the tropical oceans (Tan and Jakob 2013). The IR-only regimes also behave well over Southeast China (Fig. 1b), and thus the application of IR-only regimes is feasible in the Asian monsoon regions. In this study, the IR-only dataset of cloud regimes has a resolution of $2.5^{\circ} \times 2.5^{\circ}$ and 3-hourly intervals in 1984-2007.

To study the related precipitation activities, we use the rainfall product of the Tropical Rainfall Measuring Mission (TRMM 3B42V7). TRMM 3B42V7 has a spatial resolution of $0.25^{\circ} \times 0.25^{\circ}$ with 3 -hourly intervals (Huffman et al. 2007). It has a good performance on the diurnal cycle of rainfall over the complex surfaces in monsoon regions (H. Chen et al. 2016; G. Chen et al. 2018). Its diurnal time series are 0000, 0300, $0600, \ldots, 1800,2100$ UTC, which is consistent with the ISCCP D1 dataset for the temporal matching. For spatial matching, we average 100 precipitation grids at $0.25^{\circ} \times 0.25^{\circ}$ to match the coarse grid of ISCCP D1 at $2.5^{\circ} \times 2.5^{\circ}$. The missing data are excluded from the statistics while zero precipitation data are remained during the average process. Thus, the data of ISCCP D1 and TRMM 3B42V7 are analyzed at the same spatial/temporal resolutions. To study the relationship between cloud regimes and precipitation, we combine these two datasets for 1998-2007 when both are available. There remains a concern that TRMM tends to underestimate weak precipitation (e.g., Qin et al. 2014; Ebrahimi et al. 2017). In this study, we are cautious about rain intensity in the analysis and pay more attention to the contribution of cloud regimes to total rainfall amount, which is mainly attributed to moderate and/or intense rainfall. Thus, the bias in weak precipitation may not affect our conclusion regarding the rainfall budget. It is also found that TRMM 3B42 has a poor performance over terrains in winter. Nevertheless, it is relatively reliable in low-lying areas such as India, South China, and the Yangtze River (S. Chen et al. 2013; Rana et al. 2015). We also use the monthly precipitation of the Global Precipitation Climatology Project (GPCP) from 1979 at a resolution of $2.5^{\circ} \times 2.5^{\circ}$. The GPCP data perform well in showing the temporal and spatial distribution of global precipitation as well as its long-term change
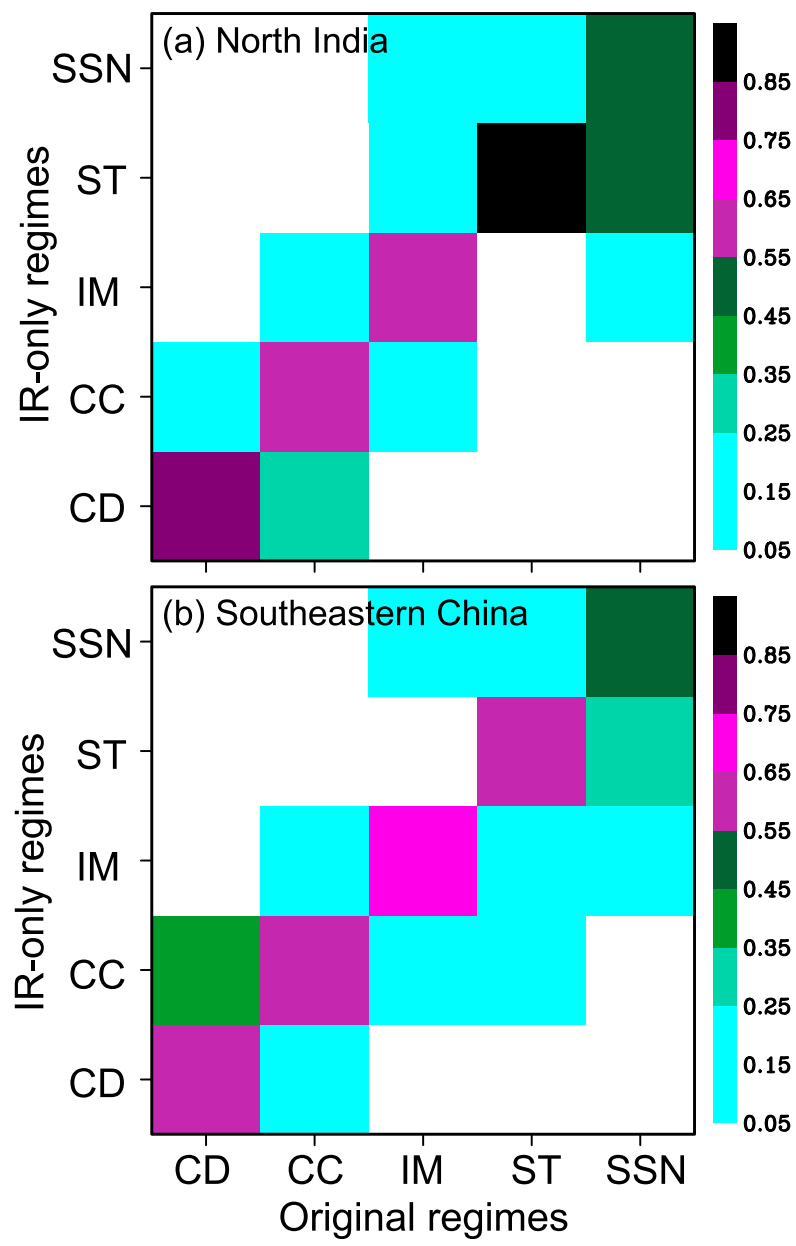

FIG. 1. A matrix plot checking how the IR-only regimes match to the original regimes in sunlit hours from 1984 to 2007 over (a) northern India and (b) Southeast China. The color bars represent the match ratio of the IR-only regime capture the "correct" regime. The convectively suppressed regimes SS1, SS2, and SS3 that have similar characteristics are merged as SSN.

(Adler et al. 2003). The data will be used to discuss the interannual variations of precipitation in section 5 .

To describe atmospheric conditions, we used the reanalysis data of 55-year Japanese Reanalysis Project (JRA-55) provided by the Japan Meteorology Agency (Kobayashi et al. 2015), which is suitable to study multiscale variabilities in winds, temperature, and humidity as well as regionality over East Asia (Chen et al. 2014). The global reanalysis JRA-55 provides 6-hourly data at a spatial resolution of $1.25^{\circ} \times 1.25^{\circ}$. To match with cloud regime data, all rainfall and reanalysis data are simply averaged into $2.5^{\circ} \times 2.5^{\circ}$ grids. At diurnal scale, we match the 6-hourly reanalysis data with two steps of 3-hourly cloud regimes or precipitation. Using JRA-55 data, we will examine the effect of atmospheric humidity on the precipitation of cloud regimes in section 4. For a better description of atmospheric humidity relating to deep convection, following the method of Tan et al. (2013), we calculate the column-averaged relative humidity (CRH) as in Bretherton et al. (2004), using the following formula: 
(a) Convectively Deep convection (CD)

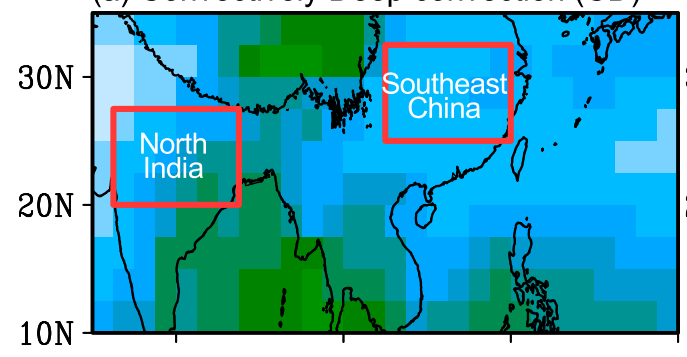

(b) Convectively Cirrus (CC)

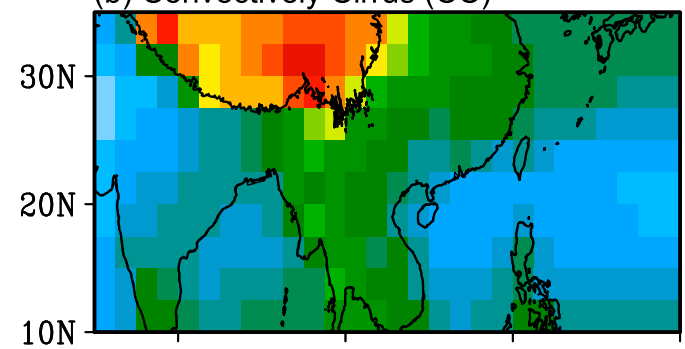

(c) Intermediate Mixture (IM)

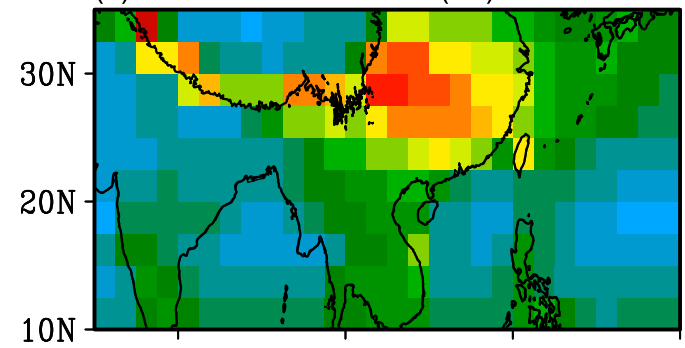

(d) Suppressed Trade cumulus (ST)

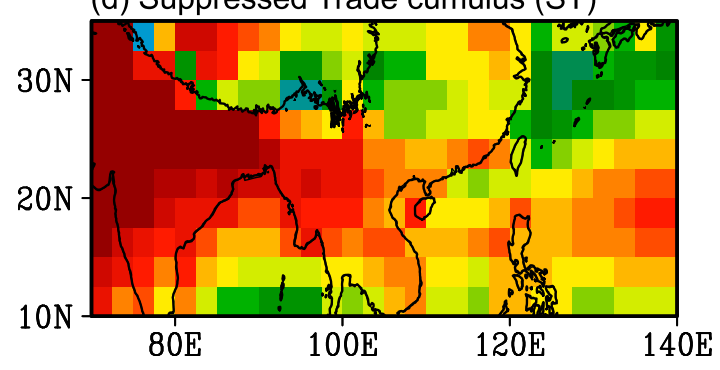

(e) Suppressed Stratocumulus (SS1)

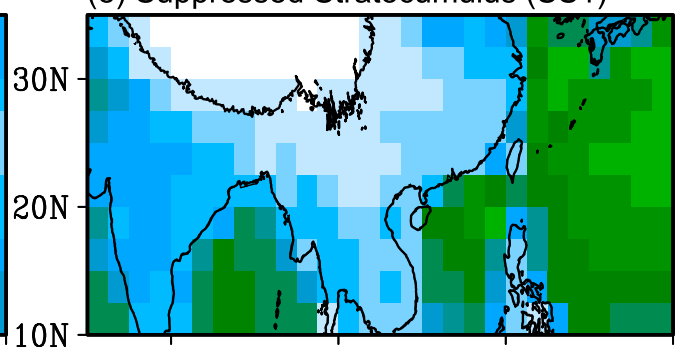

(f) Suppressed Stratocumulus (SS2)

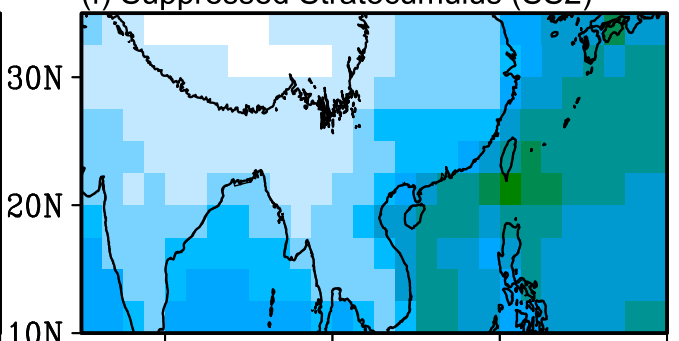

(g) Suppressed Stratocumulus (SS3)

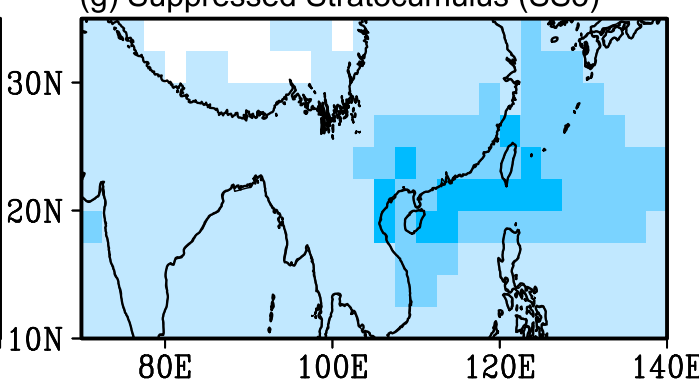

0

$\begin{array}{lllll}0.1 & 0.2 & 0.3 & 0.4 & 0.5\end{array}$ Occurrence of cloud regimes

FIG. 2. (a)-(g) Spatial distribution of annual occurrence frequency of cloud regimes in the Asian monsoon region averaged in $1984-2007$. In (a), the red boxes represent northern India $\left(72.5^{\circ}-87.5^{\circ} \mathrm{E}, 20^{\circ}-27.5^{\circ} \mathrm{N}\right)$ and Southeast China $\left(105^{\circ}-120^{\circ} \mathrm{E}, 25^{\circ}-32.5^{\circ} \mathrm{N}\right)$. The dashed lines denote the elevation at an interval of $3000 \mathrm{~m}$.

$$
\mathrm{CRH}=\frac{\int q d p}{\int q s d p} .
$$

The variable $q$ denotes specific humidity, while $q s$ denotes saturated specific humidity. The vertical integral is calculated from the surface to $300 \mathrm{hPa}$.

\section{Spatial and temporal distributions of cloud regimes}

Figure 2 shows the spatial distribution of the annual average occurrence frequency of seven cloud regimes in the Asian monsoon regions. The most convectively active regime $\mathrm{CD}$ is pronounced over the Bay of Bengal, the seas around the Philippines, and the Tibetan Plateau with an occurrence frequency of 0.1-0.225 (Fig. 2a). Another convectively active regime $\mathrm{CC}$ tends to occur over Indochina, eastern China, and the Tibetan Plateau (Fig. 2b). Its occurrence frequency is about 0.2 over Indochina and eastern China and reaches $0.3-0.45$ over the Tibetan Plateau. The terrain-related cloud regimes over the Tibetan Plateau should be distinguished from the regimes in low-lying regions. Some medium-level clouds may be misidentified as deep convection because of the higher cloud base and cloud top over high-elevation areas. A high frequency of $\mathrm{CD} / \mathrm{CC}$ is thus observed over the Tibetan Plateau, and similar 
results can be obtained using the Himawari- 8 cloud product (Yang et al. 2020). The convectively active regimes over the high elevation thus are not "convectively active" as those in low-lying regions. To ensure the reliability of the results, the cloud regimes over orography are not considered in the analysis of regional differences. The intermediate regime IM is dominant over the Himalayan foothills and eastern China with a frequency of 0.25 0.4 (Fig. 2c). The convectively suppressed regime ST is most widely observed in the Asian monsoon regions, especially over South Asia where its occurrence frequency exceeds 0.5 (Fig. 2d). The convectively suppressed regimes SS1, SS2, and SS3 mainly occur over oceans and manifest as marine stratocumulus (Figs. 2e-g), and thus they are combined as SSN in this study.

Figure 3 shows the seasonal and latitudinal variations of cloud regimes over South Asia and East Asia. Over South Asia, the ST has the highest occurrence of $\sim 0.5$ in $10^{\circ}-25^{\circ} \mathrm{N}$ (low-lying areas) in spring, and the IM has a notable peak of $\sim 0.38$ over the Himalayas near $28^{\circ} \mathrm{N}$ (Fig. 3a). The CD (CC) is suppressed in low-lying areas but relatively active over the Tibetan Plateau with a peak of $\sim 0.23(\sim 0.4)$. This does not mean that there are more convective activities over the plateau. Nevertheless, it shows that the clouds over the plateau in spring (and summer) are easier to develop to a high level than those in other seasons, as shown in Yang et al. (2020). In summer, the CD increases notably at most latitudes of South Asia, with a peak occurrence of $\sim 0.48$ in the Bay of Bengal (Fig. 3b), since the warm and moist air mass dominates in the summer monsoon season (Sabin and Pauluis 2020). The CC regime also increases to about $0.3-0.4$ in the low-lying areas. The increase of convectively active regimes is largely related to monsoon activities. Some studies also showed that aerosols have a significant impact on the generation of convective clouds (Lau et al. 2006; Z. Li et al. 2019; Zhao et al. 2020). The intermediate regime IM slightly increases to a frequency of $\sim 0.2$ in most low-lying areas but decreases around the Himalayan foothills. The convectively suppressed regime ST decreases largely from spring to summer and the SSN even becomes negligible. In autumn, the CD decreases to $\sim 0.1$ on land and $\sim 0.2$ in the Bay of Bengal and the $\mathrm{CC}$ decreases as well (Fig. 3c), which is consistent with the withdrawal of the summer monsoon. In winter, the $\mathrm{CD} / \mathrm{CC}$ are negligible in lowlying areas where the ST becomes dominant (Fig. 3d). The IM again becomes notable over the Himalayas as in spring and autumn, suggesting that intermediate regime in cold seasons has a strong dependence on terrain effects. Therefore, we see a strong seasonal change of the convectively active and intermediate regimes $(\mathrm{CD} / \mathrm{CC} / \mathrm{IM})$ against the convectively suppressed regime (ST) in low-lying areas, and the $\mathrm{CD} / \mathrm{CC}$ against $\mathrm{IM} / \mathrm{ST}$ around the Himalayan foothills.

Over the tropical ocean (south of $23^{\circ} \mathrm{N}$ ) of East Asia, the cloud regimes show a similar seasonal cycle as those in lowlying areas of South Asia. It is manifested as the CD, CC, and IM increase from spring to summer and then gradually decrease in autumn and winter, while ST and SSN are opposite (Figs. 3e-h). Over the landmass (north of $23^{\circ} \mathrm{N}$ ), the intermediate regime IM is dominant in spring (Fig. 3e). The springtime CD (CC) related to deep convection have a slightly large occurrence of $0.1(0.2)$ compared to those on the ocean. The features seem to coincide with the spring rainfall prevailing over Southeast China where a quasi-stationary front is located (Tian and Yasunari 1998). In summer, the CD increases notably under the influence of monsoon systems. However, the occurrence frequency of $\mathrm{CD} / \mathrm{CC}$ is less than that over South Asia (Figs. 3b,f), indicating the fewer convective systems or less convective atmospheric states in East Asia compared to South Asia. The IM is relatively inactive in summer, which is similar to that at the Himalayan foothills. However, it still has a comparable occurrence as $\mathrm{CC}$, suggesting the preferred occurrence of midlevel stratiform clouds over East Asia (Yu et al. 2001; Li et al. 2004). The convective regimes CD and CC decline with the retreat of summer monsoon in autumn and CD almost decreases to zero in winter, while IM and ST become dominant (Figs. 3g,h). The seasonal change of cloud regimes over East Asia is thus shown as $\mathrm{CD} / \mathrm{CC}$ against IM/ST. Overall, the convectively active regimes occur frequently over both South and East Asia in warm season, while the convectively suppressed regimes dominate in cold season, corresponding to the seasonal progress of monsoon. One of the differences between the two key regions is that the $\mathrm{CD} / \mathrm{CC}$ over East Asia have a relatively small seasonal change and the IM/ST are obvious throughout the year. The regional differences are probably related to the terrain effects or prevailing weather systems (such as fronts).

Figure 4 further shows the diurnal variations of cloud regimes over the monsoonal landmass of northern India and Southeast China, where the South Asian monsoon and East Asian monsoon prevail respectively (red boxes in Fig. 2a). Over northern India, the $\mathrm{CD} / \mathrm{CC} / \mathrm{IM}$ relating to convection are pronounced in June-September with significant diurnal variations (Figs. $4 \mathrm{a}-\mathrm{c}$ ). In this period, the CD increases in the afternoon (1500 LST) and reaches a dominant diurnal peak of $\sim 0.36$ in 1800-2100 LST (Fig. 4a). It indicates the development of deep convection under warm moist conditions in the summer monsoon season. The $\mathrm{CC}$ has a diurnal peak at late night to early morning (0000-0600 LST), with a lag of hours to the diurnal peak of CD (Figs. 4a,b). It seems to form the dissipation of deep convection. The results agree with previous studies that there exists a subdaily transition from the CD to CC regimes (Tan et al. 2013; Tan and Jakob 2013). The IM tends to grow in the morning after sunrise and maximizes near noon (Fig. 4c). Its diurnal peak is several hours prior to that of $\mathrm{CD}$, which can be regarded as the early stage of thermal convection (Tan et al. 2015). The shifting of diurnal phase in Figs. 4a-c suggests that IM may develop as $\mathrm{CD}$ at late afternoon and dissipate as $\mathrm{CC}$ after midnight. Further analysis confirms that $\sim 45 \%$ of the noon-afternoon IM events are transformed into $\mathrm{CD} \sim 6 \mathrm{~h}$ later at late afternoon or evening, while $\sim 72 \%$ of the $\mathrm{CD}$ events at night dissipate as $\mathrm{CC}$ at late night or early morning (figure not shown). It shows a diurnal cycle of convective activities in response to diurnal solar heating. In a robust contrast, the convectively suppressed regime ST dominates other months with a frequency of more than 0.5 (Fig. 4d). These large changes in patterns suggest that the strong contrast between wet and dry seasons over northern India (Mooley and Parthasarathy 1984; Sahai et al. 2000) are also well defined by cloud regimes. 


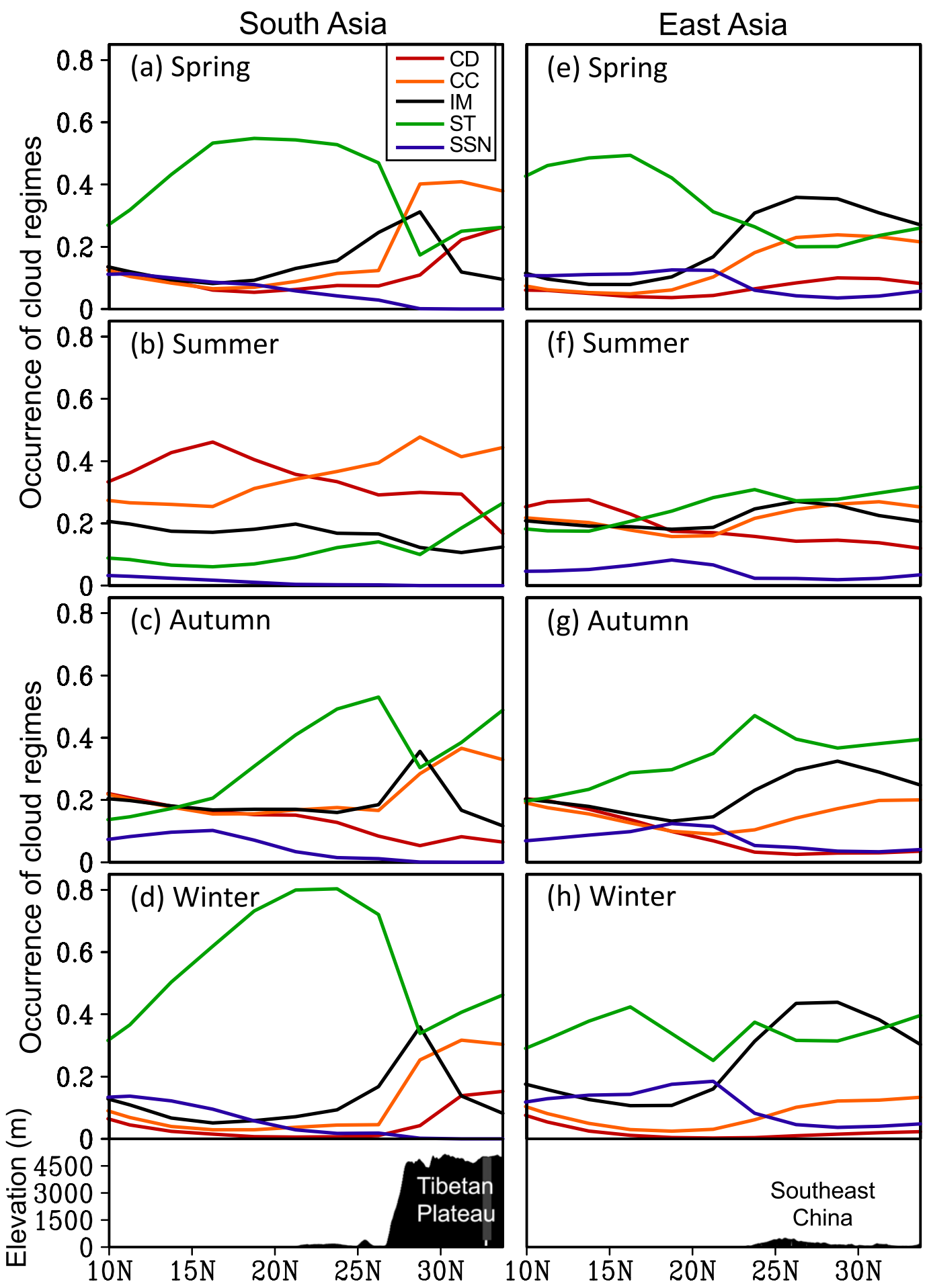

FIG. 3. Seasonal variations of cloud regimes averaged at (a)-(d) $85^{\circ}-95^{\circ} \mathrm{E}$ and (e)-(h) $110^{\circ}-120^{\circ} \mathrm{E}$. The terrains are denoted at the bottom panels. The seasons are defined as spring (March-May), summer (June-August), autumn (September-November), and winter (December-February). 

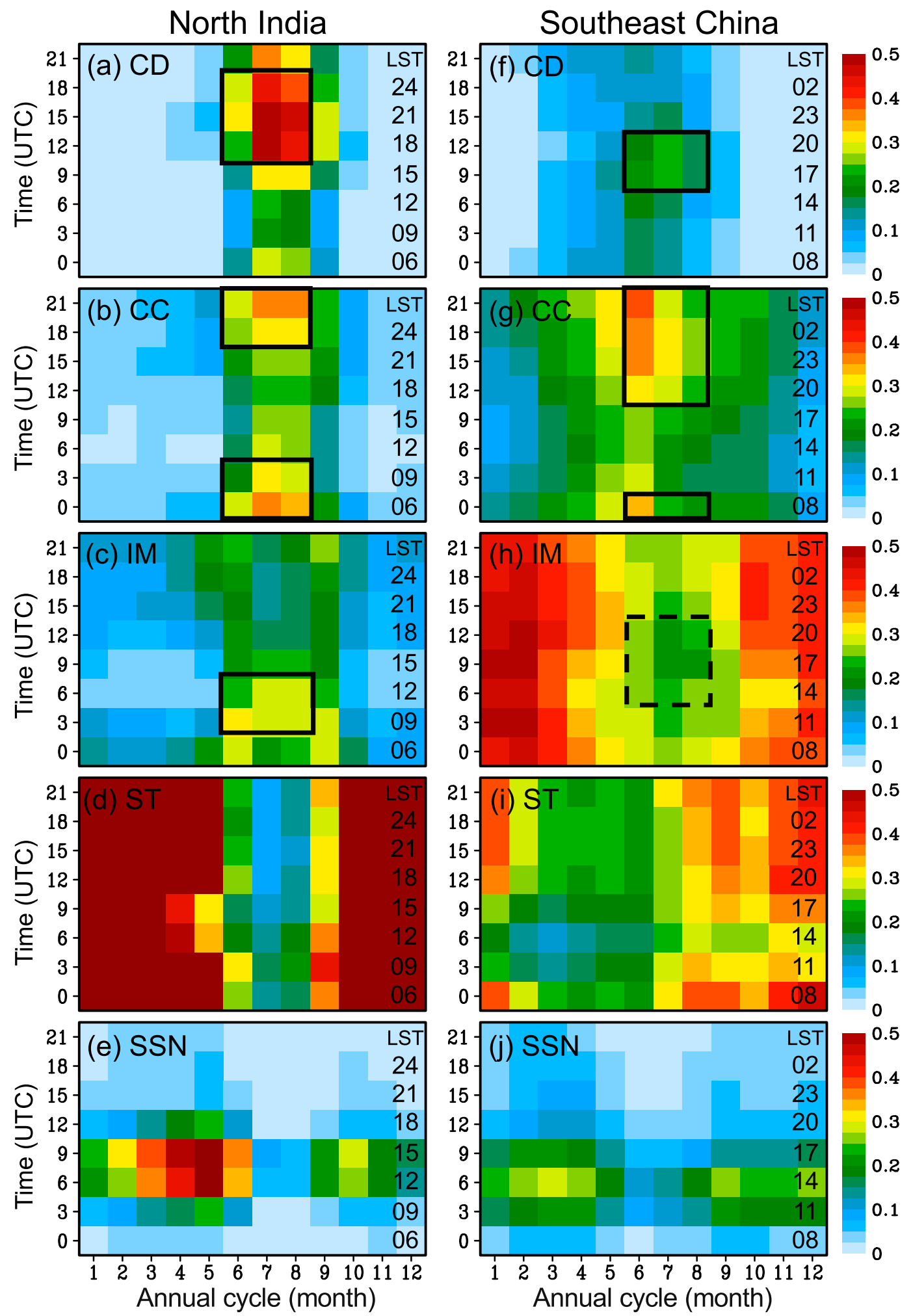

FIG. 4. Diurnal variations of cloud regimes over (a)-(e) northern India and (f)-(j) Southeast China in each month. The colors shading indicates the occurrence frequency of cloud regimes. Local standard time is marked along the $y$ coordinate to the right. The black solid (dotted) boxes denote the diurnal maximum (minimum) of $\mathrm{CD} / \mathrm{CC} / \mathrm{IM}$ in summer monsoon season. 
Over Southeast China, the convective regime CD mainly occurs in March-September (Fig. 4f), which is consistent with the prolonged rainy season compared to northern India (Ding 1992; Tian and Yasunari 1998). In spring, the CD has a relatively large frequency from late night to early morning. Its diurnal peak is shifted to late afternoon (1700-2000 LST) in summer, although the frequency in the morning hours remains obvious and is marginally smaller than the late-afternoon peak. This morning feature is different from northern India where the afternoon peak of $\mathrm{CD}$ is dominant. The diurnal cycles of $\mathrm{CD}$ are highly analogous to those of rainfall that are different in the two key regions (e.g., Sen Roy and Balling 2007; Sahany et al. 2010; Chen 2020). The CC regime over East Asia also occurs in a relatively long period from spring to autumn compared to that over northern India (Fig. 4g). At subdaily time scale, the $\mathrm{CC}$ increases from evening to early morning, with a lag of hours to $\mathrm{CD}$, and thus it denotes the diurnal dissipating stage of convection.

Over Southeast China, the IM is dominant in OctoberApril, whereas it is suppressed in summer particularly in the daytime (Fig. 4h). Its seasonal and diurnal cycles are significantly different to those over northern India with a summer daytime peak (cf. Figs. 4c,h). The IM over East Asia corresponds to the midlevel stratiform clouds that are prevailing at the lees of the Tibetan Plateau in the cold seasons (Yu et al. 2001; $\mathrm{Li}$ and $\mathrm{Gu}$ 2006). As a comparison, the ST regime is more dominant in the cold seasons over northern India than that over Southeast China (Figs. 4d,i). Given that ST is at a lower convective rank than IM, the prevailing cold-season weather state over South Asia is less convective than that over East Asia. The convectively suppressed regime SSN in the two regions is active in cold months with a daytime peak (Figs. 4e,j). Therefore, the cloud regimes related to deep or intermediate convection $(\mathrm{CD} / \mathrm{CC} / \mathrm{IM})$ are characterized by the evident regional differences in terms of seasonal and diurnal cycles, suggesting that the cloud-precipitation systems may vary largely between South Asian and East Asian monsoon regions.

\section{Relationship of cloud regimes and precipitation in the Asian monsoon regions}

\section{a. Precipitation probability under different cloud regimes}

We examine the precipitation activities associated with cloud regimes in the Asian monsoon regions, with emphasis on precipitation probability in this subsection. First, the occurrence of a rainfall event is defined when the TRMM rain rate averaged at any given grid of $2.5^{\circ} \times 2.5^{\circ}$ exceeds $0.1 \mathrm{~mm} \mathrm{day}^{-1}$. We also check the events with rain rate exceeding the higher thresholds of 1 and $10 \mathrm{~mm} \mathrm{day}^{-1}$, so that we can examine the possible link of cloud regimes to the occurrence of moderate and intense rainfalls. Here, we focus on the relationship of cloud regimes and rainfall in the boreal summer (JJA) and winter (DJF).

Figure 5a shows the probability of different rain rate thresholds related to the cloud regimes over northern India. The summertime $\mathrm{CD}$ is accompanied by the high precipitation probability (bar in light red of the first column) up to $93 \%$. The
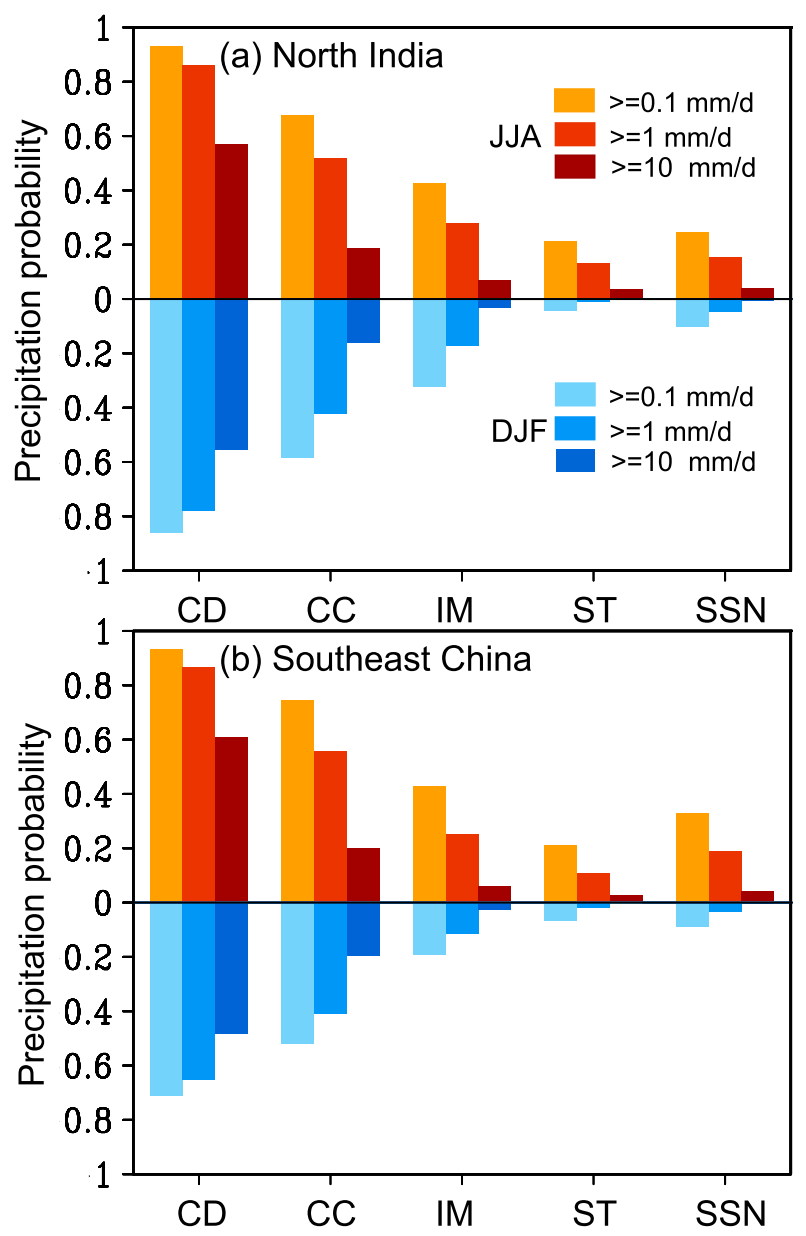

FIG. 5. Precipitation probability under different cloud regimes. The rain rate averaged at the grid of $2.5^{\circ} \times 2.5^{\circ}$ with thresholds exceeding $0.1,1$, and $10 \mathrm{~mm}$ day $^{-1}$ indicating light, moderate, and intense rainfall, respectively. The bars in warm colors represent JJA, and those in cold colors represent DJF.

actual probability of rainfall may be even larger because the TRMM data tend to underestimate weak precipitation. About $86 \%(57 \%)$ of the CD occurrence has the area-averaged rain rate exceeding 1 (10) $\mathrm{mm} \mathrm{day}^{-1}$, as shown by the bar in moderate (dark) red. It suggests that $\mathrm{CD}$ generally results in moderate and even intense rainfall. The summertime CC also has a high probability of rainfall $(\sim 68 \%)$ and at least moderate rainfall $(\sim 52 \%)$. However, its probability of producing intense rainfall reduces to $\sim 19 \%$, which is much smaller than that of $\mathrm{CD}$, implying that it is less convective than $\mathrm{CD}$. Overall, the $\mathrm{CD} / \mathrm{CC}$ can be regarded as the prevalent cloud regimes producing rainfall, in which $\mathrm{CD}$ (CC) is mainly related to the moderate to intense (light to moderate) rainfall. Many other factors such as water vapor, thermal conditions, and aerosols may cause the differences in the intensity of deep convective precipitation (e.g., Goswami et al. 2006; Li et al. 2016; Dong et al. 2018; Su et al. 2020). Figure 5a also shows that the intermediate regime IM has a probability of $43 \%$ producing rainfall and of $\sim 6 \%$ producing intense rainfall, 

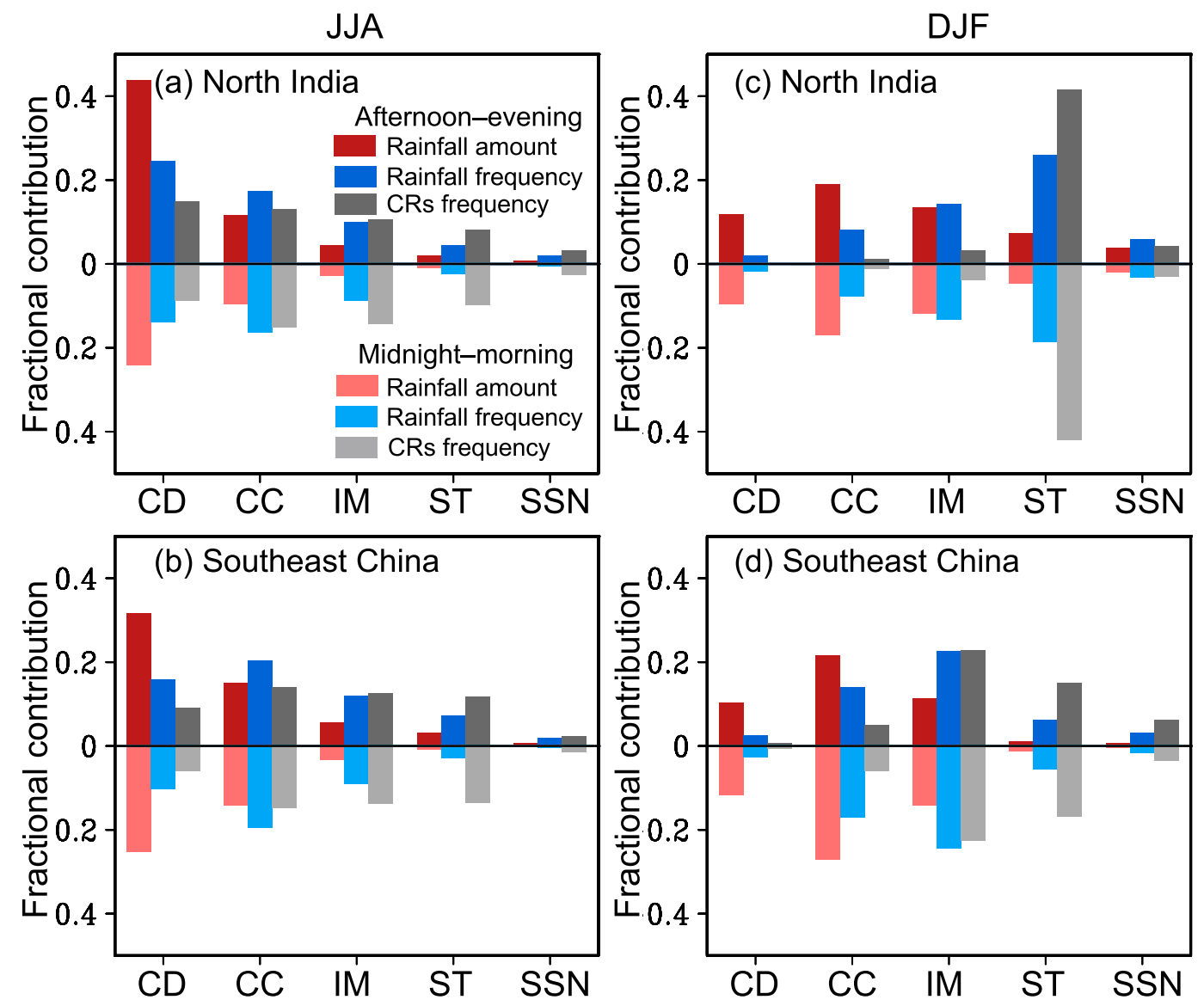

FIG. 6. Fractional contribution of cloud regimes to accumulative rainfall amount and frequency in JJA and DJF. The columns in red (blue) represent accumulative rainfall amount (frequency) and those in gray represent frequency of cloud regimes (CRs). The upper columns represent the contributions in the afternoon-evening hours, and the bottom columns represent that in the midnight-morning hours. The fractional contributions of all the cloud regimes to rainfall amount (frequency) add up to 1 .

which are lower than those of CD/CC. The other convectively suppressed regimes (ST and SSN) have even lower rainfall probabilities. Therefore, from the convectively active to suppressed regimes, we observe a decrease in rainfall probability and a much larger decrease in intense rainfall in summer, which is consistent with Tan et al. (2013). The cloud regimes over Southeast China have similar distributions of precipitation probabilities (Fig. 5b). Therefore, the cloud regimes, as an indicator of different convective conditions, are closely related to the rainfall activities over the Asian monsoon regions.

Figure 5a also shows that the rainfall probabilities of convective regimes $\mathrm{CD} / \mathrm{CC}$ in winter (blue bars) are comparable to those in summer over northern India. The occurrences of $\mathrm{CD} / \mathrm{CC}$ thus generally cause rainfall and even intense rainfall regardless of summer or winter. The IM/ST/SSN regimes have smaller rainfall probabilities in winter than in summer. These less convective regimes seem to have more difficulty in producing rainfall under cold and dry conditions India. Over Southeast China, the rainfall probabilities of all cloud regimes in winter are smaller than those in summer (Fig. 5b). In particular, the rainfall probabilities of wintertime $\mathrm{CD} / \mathrm{CC} / \mathrm{IM}$ are considerably smaller than the summertime one. Overall, the deep convective or intermediate regimes ( $\mathrm{CD} / \mathrm{CC} / \mathrm{IM})$ have more nonprecipitating features in winter over Southeast China compared to northern India.

\section{b. Contribution of cloud regimes to rainfall budget}

We further examine the relative importance of cloud regimes to the rainfall budget. We estimate the fractional contributions of accumulative rainfall amount (frequency) by each cloud regime. The fractional contributions in the hours of afternoon-evening ( 1200-2300 LST) and midnight-morning ( $\sim 0000-1100$ LST) are calculated to clarify the influence of diurnal variations of cloud regimes. These two parts are plotted separately in the upper and bottom columns with both positive axis in Fig. 6 . The difference in the length between the upper and bottom columns denotes the diurnal cycle, while the summed length of columns denotes the accumulative daily contribution by any given cloud regime. Note that the contributions of cloud regimes to rainfall budget not only depend on their occurrence frequency (section 3), but also rely on their associated precipitation probability and intensity (section $4 \mathrm{a}$ ). 
Figure 6 shows the contributions of each cloud regime to the total rainfall amount (frequency) in JJA and DJF. Over northern India, the $\mathrm{CD}(\mathrm{CC})$ contributes $\sim 68 \%(\sim 21 \%)$ of the total rainfall amount in summer, as denoted by a sum of upper and bottom columns in red (Fig. 6a). Only $\sim 7 \%$ of the total rainfall amount is attributed by IM and much less by the other convectively suppressed regimes. The $\mathrm{CD}$ (CC) regime also contributes $\sim 39 \%(\sim 34 \%)$ of the total rainfall frequency. Therefore, the convectively active regimes are regarded as the major contributors to summer monsoon rainfall budget over northern India. At diurnal scale, the CD has a larger fractional contribution to the total rainfall amount in the afternoon hours ( $\sim 4 \%$; upper column) than that in the morning hours ( $\sim 24 \%$; bottom column). The CD-related rainfall is thus responsible for the diurnal variations of summer rainfall. The difference is because that $\mathrm{CD}$ has a larger occurrence in the afternoon hours $(\sim 15 \%)$ than that in the morning hours $(\sim 9 \%)$ and a slightly higher rainfall intensity (not shown). The frequent convection in the late afternoon to early evening thus accounts for the pronounced diurnal peak of rainfall over northern India (e.g., Krishnamurti and Kishtawal 2000; Sen Roy and Balling 2007). The other cloud regimes (IM/ST/SSN) have small contributions to both the daily mean and diurnal cycle of summer rainfall.

In winter, the $\mathrm{CD}$ contributes $\sim 21 \%$ of the total rainfall amount (Fig. 6c), which is much less than that in summer. The CC (IM) regimes contribute $\sim 36 \%(\sim 25 \%)$ of the rainfall amount. The $\mathrm{CD} / \mathrm{CC} / \mathrm{IM}$ regimes are thus the major contributors to the winter rainfall amount, though they have a low occurrence frequency. These rainfall-bearing cloud regimes have comparable fractional contributions in the afternoon-evening and midnight-morning hours. They correspond to a small diurnal cycle of rainfall in winter, in contrast to those in summer. The ST regime has a very high occurrence frequency $(\sim 83 \%)$ and contributes $\sim 44 \%$ of the rainfall frequency. The ST-related rainfall is likely drizzle and has a very small fractional contribution of rainfall amount.

The CD/CC also contribute a major portion of the summer rainfall budget over Southeast China (Fig. 6b). The fractional contribution of CD is estimated as $\sim 57 \%(\sim 26 \%)$ of the total rainfall amount (frequency), which is considerably less than that over northern India. The difference is mainly due to the relatively low occurrence frequency of $\mathrm{CD}$ compared to its counterpart over northern India. Another rain-bearing regime CC contributes $\sim 29 \%$ of the total rainfall amount. At diurnal scale, the CD contributes $\sim 32 \%(\sim 25 \%)$ of the total rainfall amount in the afternoon (morning) hours. The diurnal difference $(7 \%)$ is much smaller than that $(\sim 20 \%)$ over northern India. Although $\mathrm{CD}$ has a marginally high occurrence frequency in the afternoon hours, its related rainfall intensity is relatively large in the morning hours (not shown). The CD-related rainfall amount thus has a morning feature comparable to the afternoon peak over Southeast China, which is distinct from the dominant afternoon peak over northern India. The convective rainfall in the morning hours on land over East Asia is closely related to the enhanced monsoon southerlies at night that transport moisture to the mei-yu frontal zone (Yu et al. 2007; G. Chen et al. 2009a,b, 2013; H. Chen et al. 2010; G. Chen 2020).

In winter, the $\mathrm{CD} / \mathrm{CC} / \mathrm{IM}$ regimes become the major contributors of rainfall amount over Southeast China (Fig. 6d), which is similar to those over northern India. Their fractional contributions are marginally large in the morning hours. On the other hand, the CC/IM regimes contribute $\sim 78 \%$ of rainfall frequency over Southeast China, which is much higher than that $(\sim 43 \%)$ over northern India.

\section{c. Contribution of cloud regimes on precipitation under different humidity}

The relationship between cloud regimes and tropical precipitation can be strongly affected by atmospheric conditions (Jakob and Schumacher 2008; Tan et al. 2013). The deep convective systems can be divided into two major types, depending on whether they are preferably affected by thermal instability or moisture-related processes (Chen et al. 2010; Wang et al. 2018). The thermally induced convection tends to occur in the daytime when solar heating is strong, which usually form as local and short-duration rainfall (Krishnamurti and Kishtawal 2000; Hirose and Nakamura 2005; Romatschke et al. 2010). Another type is the moisture-related organized convection that usually occurs in the nighttime with high relative humidity, which usually produces long-duration heavy rainfall in low-lying plains or basins (Yu et al. 2007; G. Chen et al. 2017; H. Chen et al. 2018; Zhang et al. 2019). Over Asia, the atmospheric humidity show pronounced seasonal and diurnal variations with an evident regionality due to monsoon activities. Here, we further estimate the relationship of cloud regimes and precipitation with respect to the humidity in the Asian monsoon regions. We use the $\mathrm{CRH}$ (at a range from 0 to 1 ) to denote the atmosphere-column humidity as introduced in section 2 .

Figure 7 shows how each of the cloud regimes contributes to the rainfall under different atmospheric humidity in summer. The rainfall is very weak at low-CRH range below 0.6 (Figs. 7a,b), and it increases considerably at moderate-CRH range (0.6-0.8). This feature on monsoonal lands is different from the rainfall over tropical oceans that has a sharper increase at the CRH above 0.7 (Tan et al. 2013). Precipitation systems are thought to be mainly affected by thermal instability at the moderate-CRH range in which the humidity is far from saturation state. The rainfall increases faster and reaches the maximum at high-CRH range (above 0.8 ), by which the processes with high humidity are thought to be more dominant. It is obvious that the increase of rainfall with $\mathrm{CRH}$ is mostly attributed to the convective regimes, especially CD. We calculate the accumulative rainfall amount of CD (estimated by multiplying the mean daily precipitation of $\mathrm{CD}$ and the absolute occurrence of each bin of $\mathrm{CRH}$ ) at moderate- and high-CRH ranges. Over northern India, the CD-related rainfall accounts for $\sim 59 \%$ of the total CD rainfall at moderate-CRH range and $\sim 39 \%$ at high-CRH range. In contrast, over Southeast China, the CD-related rainfall is recorded mostly at high-CRH range $(\sim 55 \%)$ rather than at moderate- $\mathrm{CRH}$ range $(\sim 42 \%)$. The CD-related rainfall thus tends to occur in a high-humidity condition over Southeast China compared to northern India.

The fractional contribution of CD to rainfall also tends to increase with $\mathrm{CRH}$ (Figs. 7c,d), suggesting that the moist environment is favorable for the rainfall associated with deep convection. These increasing profiles with respect to CRH have some notable differences between the two regions. The difference can 

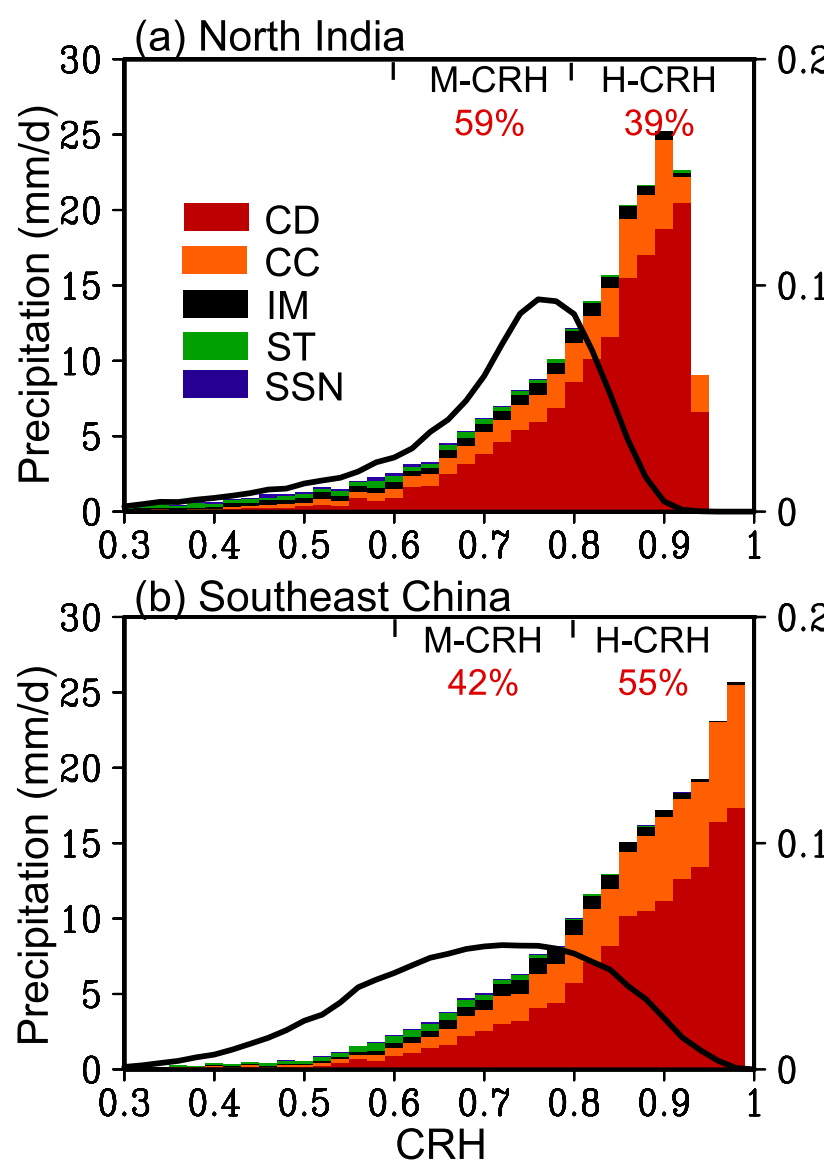

(c) North India

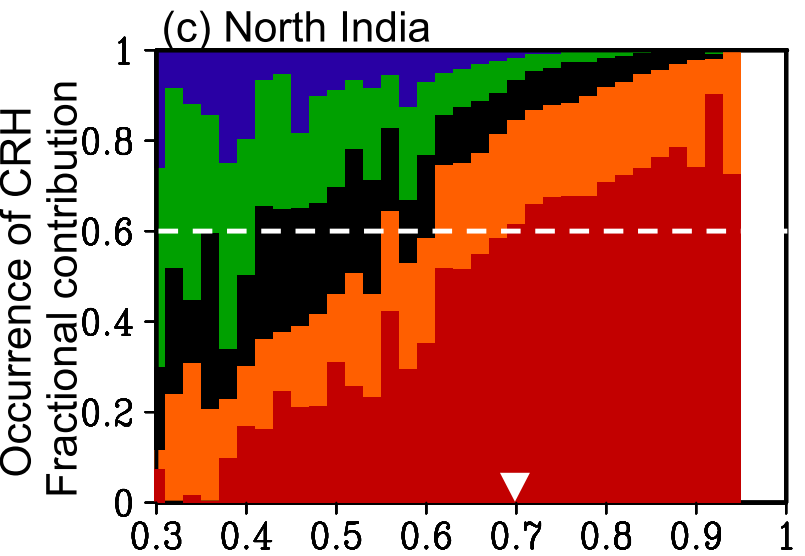

(d) Southeast China

FIG. 7. (a),(b) A histogram of the mean daily precipitation for each bin of CRH by each cloud regime in summer (JJA). The black lines indicate the relative occurrence of each bin of $\mathrm{CRH}$. The contribution percentages of the accumulative $\mathrm{CD}$ rainfall at moderate-CRH range (M-CRH) and high-CRH range (H-CRH) to the total $\mathrm{CD}$ rainfall amount are marked at the top. (c), (d) The fractional contribution of cloud regimes for each bin of $\mathrm{CRH}$. The white dotted lines denote the reference value of 0.6 , and the triangles mark the $\mathrm{CRH}$ at which CD reaches the fractional contribution of 0.6.

be denoted by the $\mathrm{CRH}$ range at which the fractional contribution exceeds a given high value such as 0.6. Over northern India, the fractional contribution increases to 0.6 at a moderate $\mathrm{CRH}$ of 0.7 (Fig. 7c). Such a dominance of CD rainfall at moderate $\mathrm{CRH}$ is likely due to the strong thermal forcings over northern India. As a comparison, the fractional contribution of $\mathrm{CD}$ is lower at moderate-CRH range over Southeast China, and it exceeds 0.6 at a high CRH of 0.82 (Fig. 7d). Unlike the condition over northern India, the thermal effect thus seems not strong enough to support the dominance of $\mathrm{CD}$ rainfall at moderate-CRH range over Southeast China, and the high-CRH condition is needed for CD rainfall to be dominant over there.

We further estimate what extent the rainfall associated with cloud regimes responds to the diurnal difference of humidity conditions (Fig. 8). In the two key regions, the CD-related rainfall increases rapidly at moderate-CRH range in the afternoon hours (Figs. 8a,b). The strong solar heating in daytime helps to drive the deep convective rainfall in a moderate moisture condition on the monsoonal lands. Over northern, the accumulative CD-related rainfall mainly occurs in the afternoon hours $(64.5 \%)$, with about $45 \%(19 \%)$ at moderate-CRH (high-CRH) range due to a larger (smaller) occurrence frequency of CRH events. Therefore, the thermally driven mechanisms may dominate the CD-related rainfall over northern India. Over Southeast China, the CDrelated rainfall in the afternoon hours accounts for $55.6 \%$ of the total CD rainfall, with about $30 \%(24 \%)$ at moderate$\mathrm{CRH}$ (high-CRH) range. The difference between the two $\mathrm{CRH}$ ranges is smaller over Southeast China than that over northern India. On the other hand, the CD-related rainfall in the morning hours increases rapidly mostly at high-CRH range (Figs. 8c,d), highlighting the importance of high moisture conditions on nocturnal rainfall. The CD-related rainfall in the morning hours contributes about $44.4 \%$ $(35.5 \%)$ of the summer rainfall over Southeast China (northern India), with $31 \%(20 \%)$ at high-CRH range. The ratio at high-CRH range in the morning is comparable to that at moderate-CRH range in the afternoon over Southeast China, while the latter one is dominant over northern India. Therefore, although the daytime thermal forcings can produce afternoon rainfall on both monsoonal lands, the nighttime moisture-related processes play an 

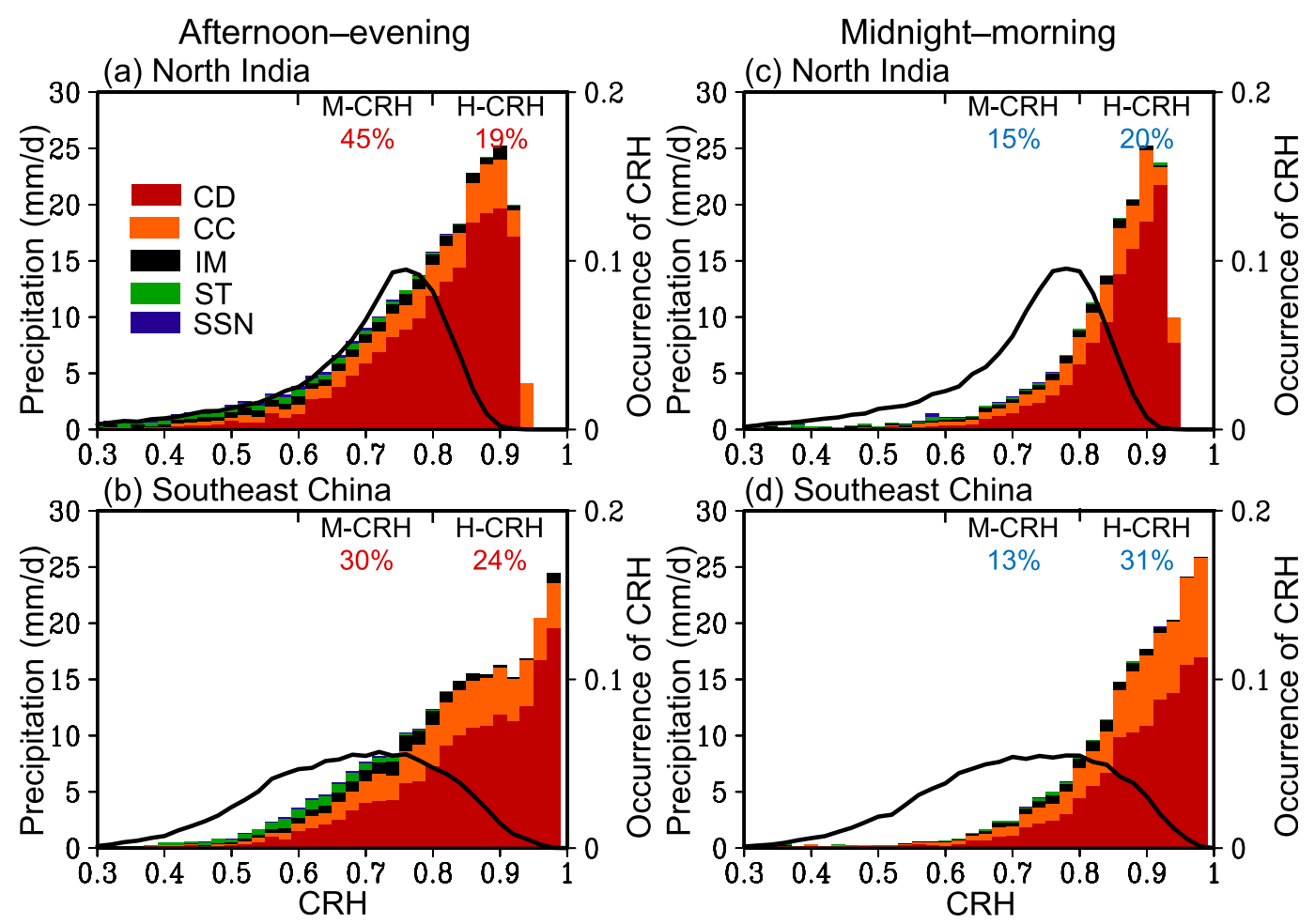

FIG. 8. A histogram of mean daily precipitation for each bin of CRH by cloud regimes in (a),(b) afternoonevening and (c),(d) midnight-morning in summer. The black lines indicate the relative occurrence of each bin of CRH. The contribution percentages of the accumulative $\mathrm{CD}$ rainfall at moderate-CRH range (M-CRH) and high-CRH range $(\mathrm{H}-\mathrm{CRH})$ to the total $\mathrm{CD}$ rainfall amount are marked at the top.

extra role in driving convection over Southeast China, resulting in the different diurnal cycles of rainfall. Other studies noted that the aerosol can also potentially modify the deep convection rainfall due to its radiative effects and microphysical effects (T. Chen et al. 2016; Zhou et al. 2020).

Figure 9 shows the winter rainfall associated with cloud regimes under different $\mathrm{CRH}$. The rainfall tends to increase with $\mathrm{CRH}$ as in summer, suggesting the importance of humidity to precipitation (Figs. 9a,b). The increase of winter rainfall with $\mathrm{CRH}$ is mostly attributed to CC/IM rather than $\mathrm{CD}$, which is different from that in summer. The fractional contributions of cloud regimes especially $\mathrm{CD}$ to precipitation do not increase with $\mathrm{CRH}$, and remain small for most $\mathrm{CRH}$ bins (Figs. 9c,d). The convectively active regimes in winter are more related to the synoptic-scale disturbances such as fronts (Hung and Kao 2010), while the effects of local humidity conditions on deep convection are usually weak.

\section{Interannual variability of cloud regimes during the summer monsoon}

\section{a. Interannual variability of cloud regimes and their} corresponding precipitation

Previous studies have shown that the Asian summer monsoon has pronounced interannual variations in precipitation and winds (Wang et al. 2001; Ding 2007). In this section, we examine the interannual variations in cloud regimes and their relationship with the Asian summer monsoon. Figures 10a-e show the spatial distribution of occurrence frequency of various cloud regimes in summer. The $\mathrm{CD}$ with a mean occurrence of $0.3-0.5$ is predominantly distributed over the Tibetan Plateau and tropical regions including the Indian subcontinent, Bay of Bengal, Indochina Peninsula, and oceans near the Philippines (Fig. 10a). The CD also exhibits a large interannual variability in these regions, with the maximum standard deviation exceeding $\sim 0.09$ in central-northern India. As a comparison, the $\mathrm{CD}$ has a relatively smaller frequency and interannual variability over Southeast China. The CC is active on land over Asia, with a maximum over the Tibetan Plateau and Indochina Peninsula (Fig. 10b). The standard deviation of CC interannual occurrence is 0.03-0.05. Overall, the interannual variation of $\mathrm{CC}$ is smaller (larger) than that of $\mathrm{CD}$ in the Indian (East Asian) monsoon regions. Some summer IM are observed over the China mainland and western India (Fig. 10c). The summer ST and SSN are mainly observed over the western Pacific, where their interannual variations are also evident (Figs. 10d,e).

Figures 10f-j show the distributions of rainfall amount from various cloud regimes and their standard deviations. The CDrelated rainfall is located in the windward coasts (such as the western coasts of India, Indochina, and the Philippines) and the southern slope of the Himalayas (Fig. 10f). This is probably due to the orographic lifting as the southwest monsoon 
(a) North India

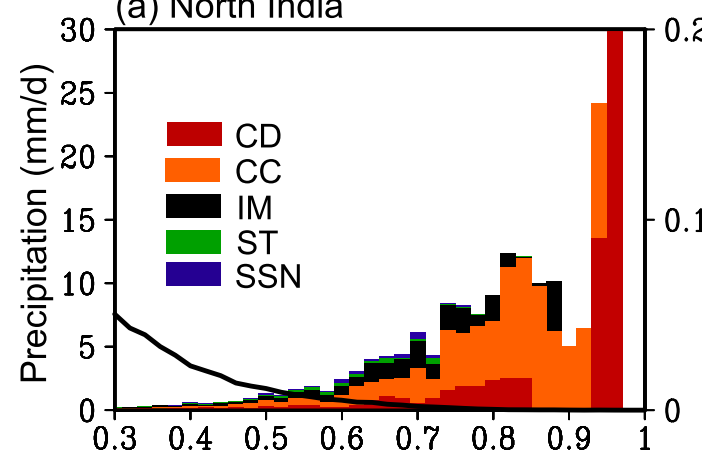

(b) Southeast China

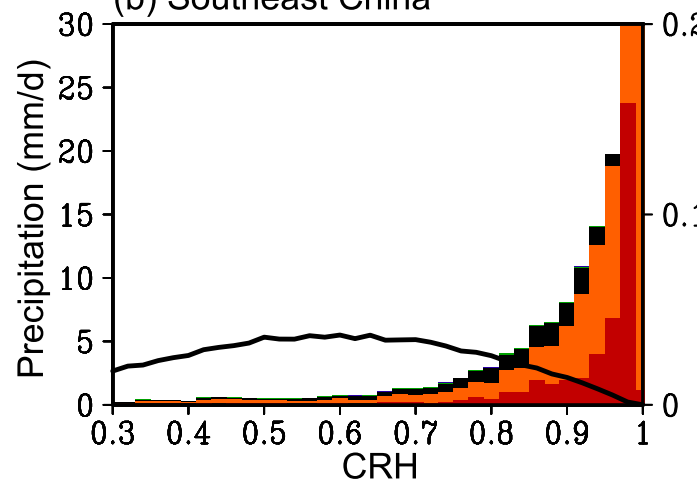

(c) North India

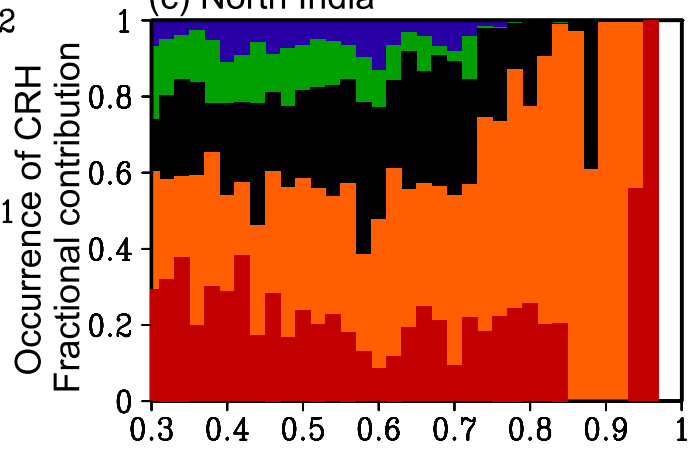

(d) Southeast China

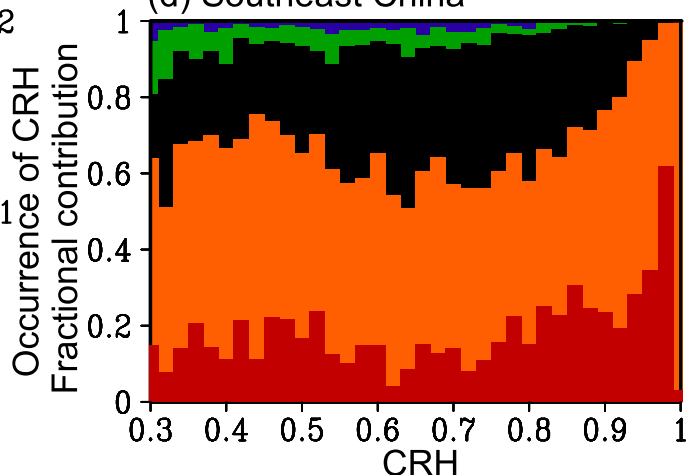

FIG. 9. As in Fig. 7, but for winter (DJF).

impinges on the coastal mountains (Xie et al. 2006). The precipitation pattern induced by $\mathrm{CC}$ is highly analogous to that by CD but at a smaller magnitude (Fig. 10g). The interannual variations also exhibit similar patterns between CD- and CC-related rainfall, with a magnitude of about $10 \%-15 \%$ of the rainfall amount, which is comparable to the variations of $\mathrm{CD} / \mathrm{CC}$ occurrence. Overall, the explained variance of $\mathrm{CD} / \mathrm{CC}$ rainfall to total summer rainfall is more than $90 \%$ in most monsoonal regions including northern India and Southeast China (figure not shown). It suggests that the $\mathrm{CD} / \mathrm{CC}$-related precipitation is the dominant factor for both the distribution and interannual variation of summer monsoon rainfall. The precipitation induced by IM is less than $100 \mathrm{~mm}$ in most areas, and that by ST and SSN is negligible (Figs. 10h-j).

\section{b. Interannual variations of cloud regimes associated with monsoon activities}

Section 4 has shown that the precipitation of convective regimes varies with humidity in seasonal and diurnal scale. During the summer season, monsoon flow is crucial for water vapor transport and moisture convergence, which may regulate the frequency of $\mathrm{CD} / \mathrm{CC}$ and their induced rainfall. Thus, we examine the relationship between $\mathrm{CD} / \mathrm{CC}$ frequency and summer rainfall and further examine whether the monsoon flow regulates the interannual variations of $\mathrm{CD} / \mathrm{CC}$ over northern India and Southeast China.

Figure 11 shows the $\mathrm{CD} / \mathrm{CC}$ frequency and summer rainfall amount over northern India and Southeast China. It is clear that the $\mathrm{CD} / \mathrm{CC}$ frequency and summer rainfall exhibit obvious interannual variations. The $\mathrm{CD} / \mathrm{CC}$ frequency is correlated with the summer rainfall over the two regions with a high correlation coefficient that passes the $99.9 \%$ confidence level. This strong relationship to rainfall suggests that the cloud regimes also manifest the interannual variations of the Asian summer monsoon systems.

Figure 12 further shows the interannual variations of $\mathrm{CD} / \mathrm{CC}$ frequency and summer monsoon activities. The column meridional water vapor flux at the southern boundary (VWVS) and the divergence of column water vapor flux (DWV) denote the moist processes of monsoon activities. The positive VWVS means the moisture transports of southerly monsoon flow. Over northern India, the VWVS fluctuates between -49 and $35 \mathrm{~kg} \mathrm{~m}^{-1} \mathrm{~s}^{-1}$ during 1984-2007, and the DWV has a range from $-0.67 \times 10^{-4}$ to $-1.0 \times 10^{-4} \mathrm{~kg} \mathrm{~m}^{-2} \mathrm{~s}^{-1}$ (Fig. 12a). The correlation coefficient between $\mathrm{CD} / \mathrm{CC}$ frequency and $\mathrm{DWV}$ is about 0.31 , indicating a weak relationship between convection occurrence and moisture conditions. The correlation coefficient between the $\mathrm{CD} / \mathrm{CC}$ frequency and the VWVS is as low as 0.05 , suggesting that the $\mathrm{CD} / \mathrm{CC}$ occurrence is not so related to the monsoon southerlies. Although the zonal component of water vapor transport is large over northern India (Yi 1995; Fujinami et al. 2014), its correlation with CD/CC frequency is not statistically significant as well. A reasonable conjecture is that the generation of convection systems over northern India is more related to strong thermal conditions rather than moisture conditions as shown in section 4c.

Over Southeast China, the VWVS exhibits a pronounced interannual variation ranging from $\sim 40$ to $\sim 180 \mathrm{~kg} \mathrm{~m}^{-1} \mathrm{~s}^{-1}$ 
(a) CD occurrence frequency

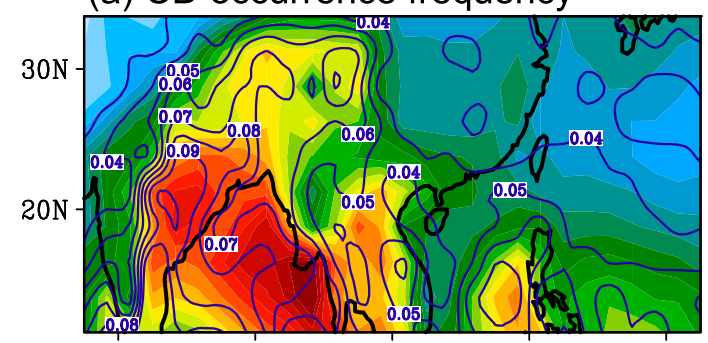

(b) CC occurrence frequency

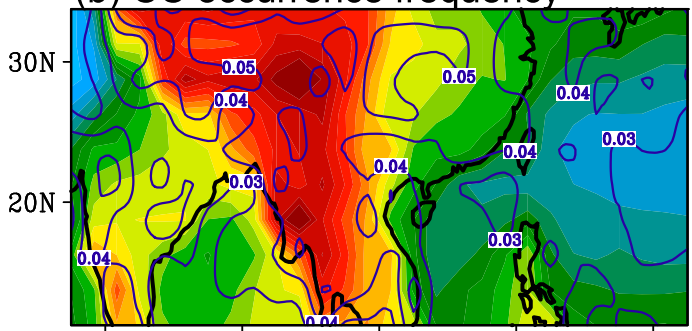

(c) IM occurrence frequency

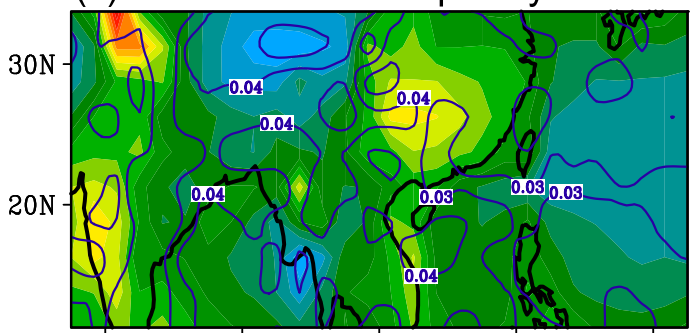

(d) ST occurrence frequency

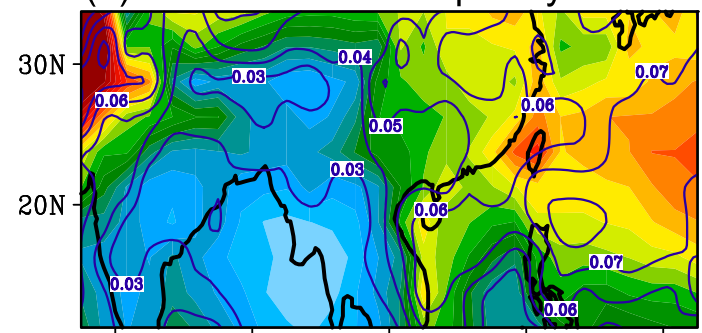

(e) SSN occurrence frequency

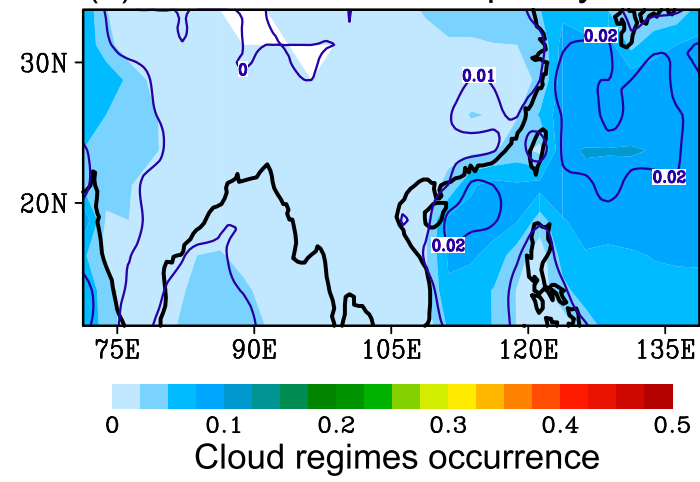

(f) CD-related rainfall

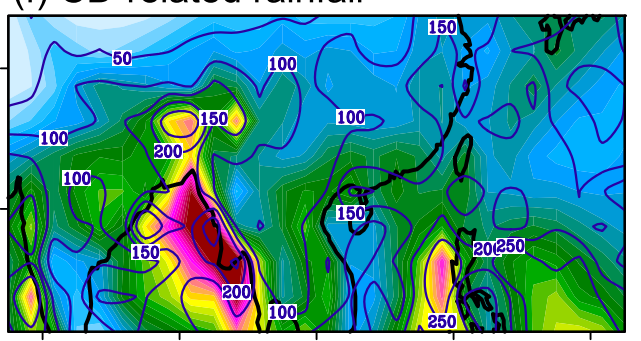

(g) CC-related rainfall

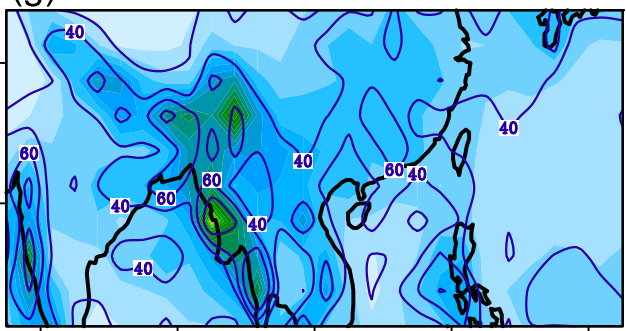

(h) IM-related rainfall

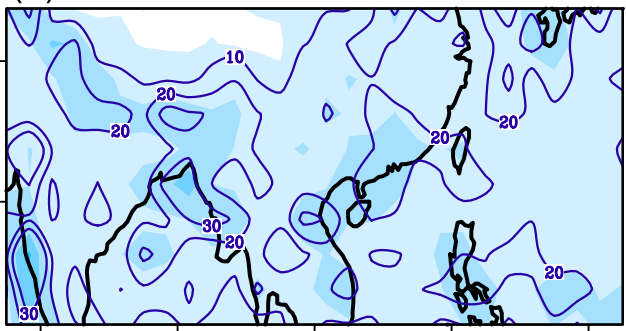

(i) ST-related rainfall

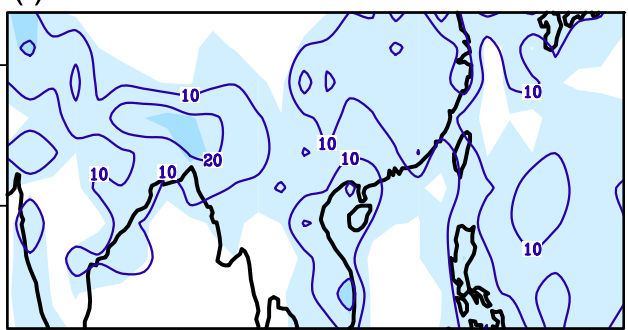

(j) SSN-related rainfall

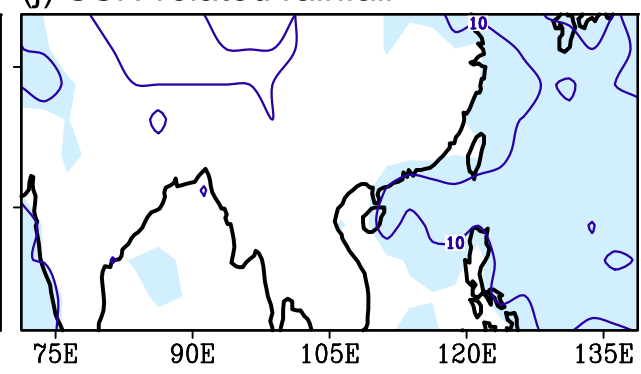

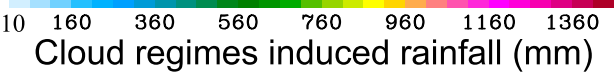

FIG. 10. (a)-(e) Spatial distribution of the occurrence frequency of summertime cloud regimes (shading) and its standard deviation (contour) in the Asian monsoon region. (f)-(j) Spatial distribution of summer average (1998-2007) rainfall produced by different cloud regimes (shading) and its standard deviation (contour). 


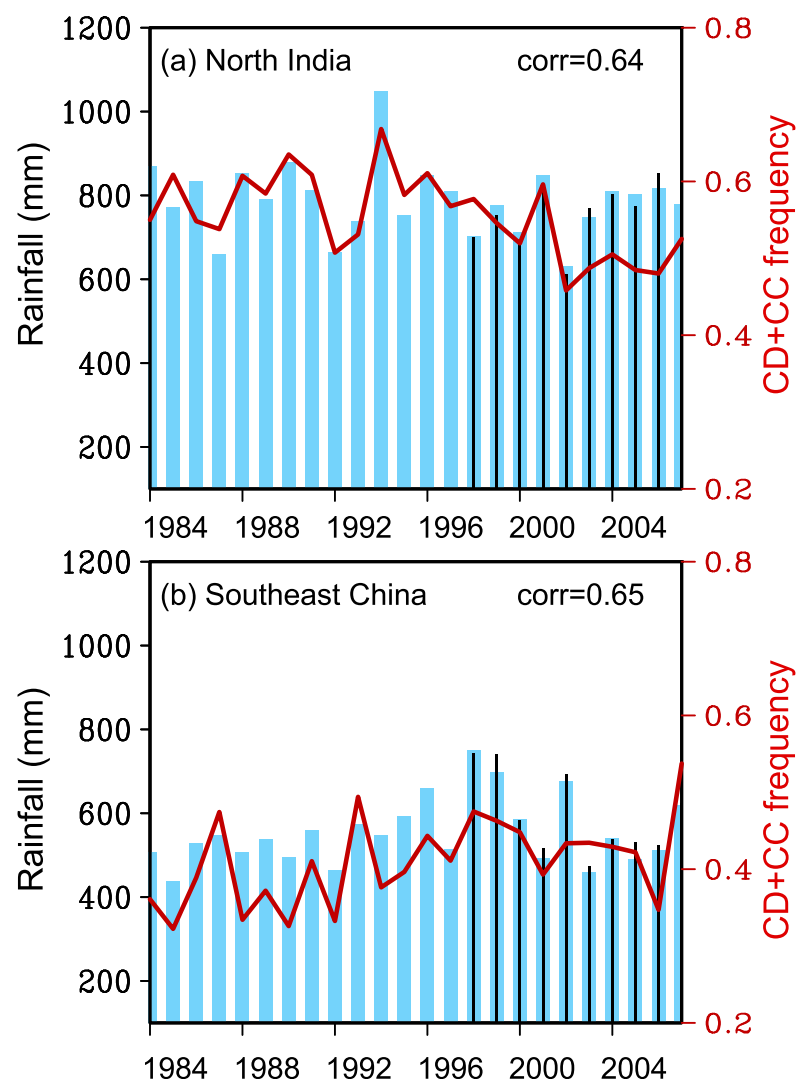

FIG. 11. Interannual variations of the occurrence frequency of summertime convectively active cloud regimes $\mathrm{CD} / \mathrm{CC}$ (red solid line) and the total summer rainfall (blue columns for GPCP rainfall; small black columns for TRMM rainfall). The correlation coefficient between $\mathrm{CD} / \mathrm{CC}$ frequency and GPCP rainfall is marked at the right top of each figure. The correlation coefficients are statistically significant at the $99.9 \%$ confidence level.

(Fig. 12b), which is much larger than that over northern India. The DWV undergoes interannual variations similar to VWVS, with a correlation coefficient of 0.61 . The correlation coefficient between DWV (VWVS) and CD/CC frequency is as high as $0.64(0.50)$. All these coefficients are statistically significant, exceeding at least the $95 \%$ confidence level, and are much higher than those over northern India. It suggests that the interannual variation of $\mathrm{CD} / \mathrm{CC}$ frequency over Southeast China is closely related to the southerly monsoon and its induced moisture convergence. The regional differences in this cloud regime-moisture relationship over Asia highlight that the cloud regimes play a key role in linking from moist monsoon flow to precipitation, which can be regarded as an important aspect of the Asian monsoon systems.

\section{Summary and discussion}

In this study, the ISCCP data have been used to study the multiscale characteristics of cloud regimes with emphasis on the regional difference in the Asian monsoon regions. We analyze the diurnal, seasonal, and interannual variations of
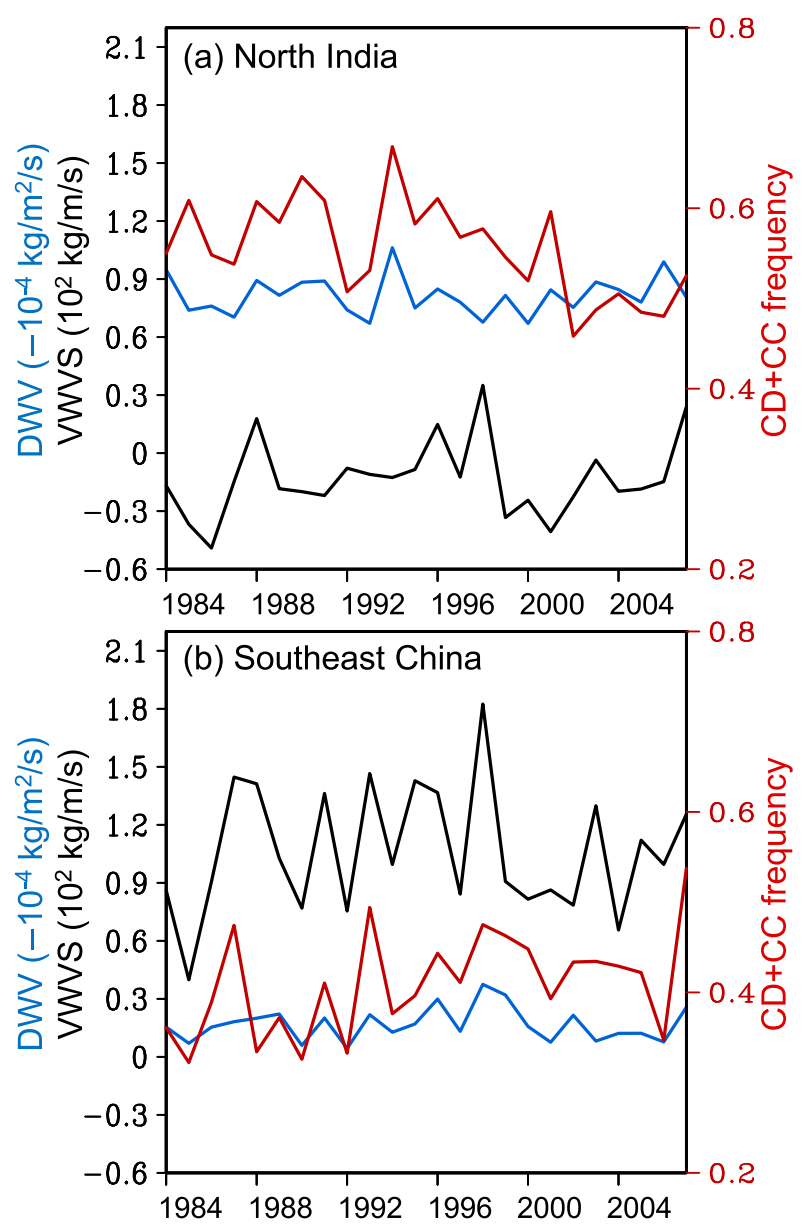

FIG. 12. Interannual variations of the occurrence frequency of the convectively active cloud regimes $\mathrm{CD} / \mathrm{CC}$ (red solid), the column meridional water vapor flux from the southern boundary (VWVS: black solid), and the divergence of column water vapor flux (DWV: blue solid, with positive values for convergence) in summer.

cloud regimes and their contribution to the rainfall budget. We also examine the cloud regime-rainfall relationship under various humidity conditions in the key regions. The results shed light on the Asian monsoon activities at a wide range of time scales, for the first time, from the perspective of cloud regimes. The main findings are summarized below.

1) The cloud regimes are found to exhibit pronounced differences in the South Asian and East Asian monsoon regions. The convectively active cloud regimes $(\mathrm{CD} / \mathrm{CC})$, related to deep convection, mainly occur in warm seasons, while the other convectively suppressed regimes dominate in cold seasons. Such a seasonal change of cloud regimes corresponds to the progress of the Asian monsoon. One of the major differences is that the $\mathrm{CD}$ regime is active in June-September with a pronounced late-afternoon peak over northern India. However, over Southeast China, the $\mathrm{CD}$ lasts for a longer period of March-September with a remarkable morning feature. The intermediate mixture regime IM also behaves differently over the two key regions. 
Over northern India, the IM occurs frequently in summer and maximizes near noon. It tends to develop as CD at late afternoon and dissipates as $\mathrm{CC}$ after midnight, showing a life cycle of thermal convection in response to solar heating. Over Southeast China, the IM prevails in cold months with a small diurnal cycle, manifesting as midlevel stratiform clouds at the lee of the Tibetan Plateau.

2) The prevalent cloud regimes that result in rainfall are objectively identified over South and East Asian monsoon regions. Over these two regions, the $\mathrm{CD}$ is mostly related to moderateto-intense rainfall, while the $\mathrm{CC}$ is closely related to light-tomoderate rainfall. These two rainy cloud regimes contribute $80 \%-90 \%$ of the total rainfall in summer monsoon season. The CD contributes a relatively large proportion of rainfall budget over northern India compared to that over Southeast China. The CD-related rainfall also determines the diurnal cycle of summer rainfall, which is characterized by an afternoon peak (morning feature) over northern India (Southeast China).

3) The cloud regime-rainfall relationship is found to be strongly regulated by the atmospheric humidity in association with monsoon activities. The rainfall contributed by the $\mathrm{CD}$ regime increases with $\mathrm{CRH}$ in summer, suggesting the importance of humidity to convective rainfall. Over northern India, the CD-related rainfall mainly occurs at moderate $\mathrm{CRH}$ in the afternoon to evening, indicating the key role of thermal forcings in producing summer rainfall of deep convection. Over Southeast China, the CD-related rainfall has a comparable proportion at moderate- $\mathrm{CRH}$ range in the afternoon-evening and at high- $\mathrm{CRH}$ range between midnight and morning. It suggests that both the thermal-induced and moisture-related processes are important for producing the rainfall of deep convection over Southeast China. The fractional contribution of $\mathrm{CD}$ to rainfall does not increase with $\mathrm{CRH}$ in winter. The results highlight a close link between cloud regimes and monsoon activities (rainfall and humidity) in both seasonal and diurnal time scales.

4) We also reveal that the interannual variations of cloud regimes and their relationship with monsoon activities vary in the Asian monsoon regions. The rainfall associated with $\mathrm{CD} / \mathrm{CC}$ is the determinant factor for the interannual variation of summer rainfall because it explains more than $90 \%$ of interannual variations of summer rainfall. The interannual variation of $\mathrm{CD} / \mathrm{CC}$ occurrence is not so related to the water vapor transports and induced convergence over northern India, where the occurrences of convective regimes are more related to the daytime thermal forcings. As a comparison, over Southeast China, the interannual variation of $\mathrm{CD} / \mathrm{CC}$ occurrence is strongly regulated by the water vapor transport and convergence of southerly monsoon flow, suggesting a close relation to the moisture-related processes. The cloud regimes thus act as a key link of regional monsoon flow to precipitation, which can be regarded as an important aspect of the Asian monsoon system.

The results of this study help to improve our understanding of the cloud-precipitation interaction in the Asian monsoon regions. Further studies in the future are needed to address the following issues. In addition to the diurnal, seasonal, and interannual variations, significant intraseasonal variability is observed in the Asian monsoon regions as well (e.g., Lau et al. 1988; Hoyos and Webster 2007; Krishnamurthy and Shukla 2007; Joseph and Sabin 2008). The intraseasonal variation of cloud regimes in the different monsoon regions and the relationship with monsoon activities is a remaining key issue to be solved. It will further improve the understanding of multiscale characteristics of the Asian monsoon from the perspective of cloud regimes. Another issue is the physical processes governing the diurnal variation of cloud regimes. Our research has pointed out that the relationship between cloud regimes and rainfall is probably regulated by thermal forcing and humidity processes. However, the detailed physical processes by which atmospheric conditions affect cloud regimes and their related precipitation deserve dedicated analyses (Jin 2006; Zelinka and Hartmann 2009). The interaction of aerosols and cloud regimes is also a key issue deserving study because of the heavy air pollution over South and East Asia (e.g., Z. Li et al. 2019). These further works help to establish a framework to understand the linkage from atmospheric conditions to cloud and further precipitation.

Acknowledgments. The authors are grateful to ISCCP for providing VIS-IR cloud regimes products (https://isccp.giss.nasa.gov/ wstates/etcluster.html), to the NOAA-Cooperative Remote Sensing Science and Technology Center at the City College of New York for providing ISCCP IR-only cloud regimes products (https://www.cessrst.org/rscg/Products/WS/tircluster.html), to NASA/GSFC for providing TRMM rainfall data (https:// gpm.nasa.gov/data-access/downloads/trmm), to WCRP GEWEX for providing GPCP rainfall data (http://eagle1.umd.edu/GPCP_ ICDR/GPCP_Monthly.html), and to JMA for providing reanalysis data (https://jra.kishou.go.jp/JRA-55/index_en.html). They also thank three anonymous reviewers for their helpful comments to improve the article. This study is supported by the National Natural Science Foundation of China (Grant 41575068), the "111-Plan" Project of China (Grant B17049), and Guangdong Province Key Laboratory for Climate Change and Natural Disaster Studies (Grant 2020B1212060025).

\section{REFERENCES}

Adler, R. F., and Coauthors, 2003: The version-2 Global Precipitation Climatology Project (GPCP) monthly precipitation analysis (1979-present). J. Hydrometeor., 4, 1147-1167, https://doi.org/ 10.1175/1525-7541(2003)004<1147:TVGPCP>2.0.CO;2.

Basu, B. K., 2007: Diurnal variation in precipitation over India during the summer monsoon season: Observed and model predicted. Mon. Wea. Rev., 135, 2155-2167, https://doi.org/ 10.1175/MWR3355.1.

Bretherton, C. S., M. E. Peters, and L. E. Back, 2004: Relationships between water vapor path and precipitation over the tropical oceans. J. Climate, 17, 1517-1528, https://doi.org/10.1175/15200442(2004)017<1517:RBWVPA > 2.0.CO;2.

Chen, G., 2020: Diurnal cycle of the Asian summer monsoon: Air pump of the second kind. J. Climate, 33, 1747-1775, https:// doi.org/10.1175/JCLI-D-19-0210.1.

— W. Wha, and T. Iwasaki, 2009a: Diurnal variation of precipitation over southeastern China: Spatial distribution and its 
seasonality. J. Geophys. Res., 114, D13103, https://doi.org/ 10.1029/2008JD011103.

$\_,-$, and $-2009 \mathrm{~b}$ : Diurnal variation of precipitation over southeastern China: 2. Impact of the diurnal monsoon variability. J. Geophys. Res., 114, D21105, https://doi.org/10.1029/ 2009JD012181.

,,-- M. Sawada, and T. Iwasaki, 2013: Influence of summer monsoon diurnal cycle on moisture transport and precipitation over eastern China. J. Geophys. Res. Atmos., 118, 3163 3177, https://doi.org/10.1002/jgrd.50337.

—, T. Iwasaki, H. Qin, and W. Sha, 2014: Evaluation of the warm-season diurnal variability over East Asia in recent reanalyses JRA-55, ERA-Interim, NCEP CFSR, and NASA MERRA. J. Climate, 27, 5517-5537, https://doi.org/10.1175/ JCLI-D-14-00005.1.

,-- W. Sha, and Z. Wen, 2017: Diurnal cycle of a heavy rainfall corridor over East Asia. Mon. Wea. Rev., 145, 33653389, https://doi.org/10.1175/MWR-D-16-0423.1.

_- R. Lan, W. Zeng, H. Pan, and W. Li, 2018: Diurnal variations of rainfall in surface and satellite observations at the monsoon coast (South China). J. Climate, 31, 1703-1724, https://doi.org/ 10.1175/JCLI-D-17-0373.1.

Chen, H., R. Yu, J. Li, W. Yuan, and T. Zhou, 2010: Why nocturnal long-duration rainfall presents an eastward-delayed diurnal phase of rainfall down the Yangtze River valley. J. Climate, 23, 905-917, https://doi.org/10.1175/2009JCLI3187.1.

,-- , and B. Wu, 2012: FY-2C-derived diurnal features of clouds in the southern contiguous China.J. Geophys. Res., 117, D18101, https://doi.org/10.1029/2012JD018125.

,-- , and Y. Shen, 2016: A new method to compare hourly rainfall between station observations and satellite products over central-eastern China. J. Meteor. Res., 30, 737-757, https://doi.org/10.1007/s13351-016-6002-5.

— J. Ji, and R. Yu, 2018: Warm season nocturnal rainfall over the eastern periphery of the Tibetan Plateau and its relationship with rainfall events in adjacent regions. Int. J. Climatol., 38, 4786-4801, https://doi.org/10.1002/joc.5696.

Chen, S., and Coauthors, 2013: Similarity and difference of the two successive V6 and V7 TRMM Multisatellite Precipitation Analysis (TMPA) performance over China. J. Geophys. Res. Atmos., 118, 13 060-13 074, https://doi.org/10.1002/ 2013JD019964.

Chen, T., J. Guo, Z. Li, C. Zhao, H. Liu, M. Cribb, F. Wang, and J. He, 2016: A CloudSat perspective on the cloud climatology and its association with aerosol perturbations in the vertical over eastern China. J. Atmos. Sci., 73, 3599-3616, https://doi.org/ 10.1175/JAS-D-15-0309.1.

Ding, Y. H., 1992: Summer monsoon rainfall in China. J. Meteor. Soc. Japan, 70, 373-396, https://doi.org/10.2151/jmsj1965.70.1B_373.

_ 2007: The variability of the Asian summer monsoon. J. Meteor. Soc. Japan, 85B, 21-54, https://doi.org/10.2151/jmsj.85B.21.

— An overview. Meteor. Atmos. Phys., 89, 117-142, https://doi.org/ 10.1007/s00703-005-0125-z.

Dong, W., Y. Lin, J. S. Wright, Y. Xie, X. Yin, and J. Guo, 2018: Precipitable water and CAPE dependence of rainfall intensities in China. Climate Dyn., 52, 3357-3368, https://doi.org/10.1007/ s00382-018-4327-8.

Ebrahimi, S., C. Chen, Q. Chen, Y. Zhang, N. Ma, and Q. Zaman, 2017: Effects of temporal scales and space mismatches on the TRMM 3B42 v7 precipitation product in a remote mountainous area. Hydrol. Processes, 31, 4315-4327, https://doi.org/ 10.1002/hyp.11357.
Fujinami, H., T. Yasunari, and A. Morimoto, 2014: Dynamics of distinct intraseasonal oscillation in summer monsoon rainfall over the Meghalaya-Bangladesh-western Myanmar region: Covariability between the tropics and mid-latitudes. Climate Dyn., 43, 2147-2166, https://doi.org/10.1007/s00382-013-2040-1.

— , T. Sato, H. Kanamori, and F. Murata, 2017: Contrasting features of monsoon precipitation around the Meghalaya Plateau under westerly and easterly regimes. J. Geophys. Res. Atmos., 122, 9591-9610, https://doi.org/10.1002/2016JD026116.

Furtado, K., P. R. Field, I. A. Boutle, C. J. Morcrette, and J. M. Wilkinson, 2016: A physically based subgrid parameterization for the production and maintenance of mixed-phase clouds in a general circulation model. J. Atmos. Sci., 73, 279-291, https://doi.org/10.1175/JAS-D-15-0021.1.

Goswami, B. N., and R. S. Mohan, 2001: Intraseasonal oscillations and interannual variability of the Indian summer monsoon. J. Climate, 14, 1180-1198, https://doi.org/10.1175/1520-0442(2001) 014<1180:IOAIVO>2.0.CO;2.

_, V. Venugopal, D. Sengupta, M. Madhusoodanan, and P. K. Xavier, 2006: Increasing trends of extreme rain events over India in a warming environment. Science, 314, 1442-1445, https://doi.org/10.1126/science.1132027.

Handlos, Z. J., and L. E. Back, 2014: Estimating vertical motion profile shape within tropical weather states over the oceans. J. Climate, 27, 7667-7686, https://doi.org/10.1175/JCLI-D-1300602.1.

Hartmann, D. L., and K. Larson, 2002: An important constraint on tropical cloud-climate feedback. Geophys. Res. Lett., 29, 1951, https://doi.org/10.1029/2002GL015835.

Hirose, M., and K. Nakamura, 2005: Spatial and diurnal variation of precipitation systems over Asia observed by the TRMM Precipitation Radar. J. Geophys. Res., 110, D05106, https:// doi.org/10.1029/2004JD004815.

Hoyos, C. D., and P. J. Webster, 2007: The role of intraseasonal variability in the nature of Asian monsoon precipitation. J. Climate, 20, 4402-4424, https://doi.org/10.1175/JCLI4252.1.

Huffman, G. J., and Coauthors, 2007: The TRMM Multisatellite Precipitation Analysis (TMPA): Quasi-global, multiyear, combined-sensor precipitation estimates at fine scales. J. Hydrometeor., 8, 38-55, https://doi.org/10.1175/JHM560.1.

Hung, C., and P. Kao, 2010: Weakening of the winter monsoon and abrupt increase of winter rainfalls over northern Taiwan and southern China in the early 1980s. J. Climate, 23, 2357-2367, https://doi.org/10.1175/2009JCLI3182.1.

Jakob, C., and G. Tselioudis, 2003: Objective identification of cloud regimes in the tropical western Pacific. Geophys. Res. Lett., 30, 2082, https://doi.org/10.1029/2003GL018367.

— , and C. Schumacher, 2008: Precipitation and latent heating characteristics of the major tropical western Pacific cloud regimes. J. Climate, 21, 4348-4364, https://doi.org/10.1175/ 2008JCLI2122.1.

— , G. Tselioudis, and T. Hume, 2005: The radiative, cloud, and thermodynamic properties of the major tropical western Pacific cloud regimes. J. Climate, 18, 1203-1215, https://doi.org/10.1175/ JCLI3326.1.

Jin, M. L., 2006: MODIS observed seasonal and interannual variations of atmospheric conditions associated with hydrological cycle over Tibetan Plateau. Geophys. Res. Lett., 33, L19707, https://doi.org/10.1029/2006GL026713.

Joseph, P. V., and T. P. Sabin, 2008: An ocean-atmosphere interaction mechanism for the active break cycle of the Asian summer monsoon. Climate Dyn., 30, 553-566, https://doi.org/ 10.1007/s00382-007-0305-2. 
Kobayashi, S., and Coauthors, 2015: The JRA-55 reanalysis: General specifications and basic characteristics. J. Meteor. Soc. Japan, 93, 5-48, https://doi.org/10.2151/jmsj.2015-001.

Kripalani, R. H., and A. Kulkarni, 1997: Climatic impacts of El Niño/La Niña on the Indian monsoon: A new perspective. Weather, 52, 39-46, https://doi.org/10.1002/j.14778696.1997.tb06267.x.

Krishnamurthy, V., and J. Shukla, 2007: Intraseasonal and seasonally persisting patterns of Indian monsoon rainfall. J. Climate, 20, 3-20, https://doi.org/10.1175/JCLI3981.1.

Krishnamurti, T. N., and C. M. Kishtawal, 2000: A pronounced continental-scale diurnal mode of the Asian summer monsoon. Mon. Wea. Rev., 128, 462-473, https://doi.org/10.1175/15200493(2000)128<0462:APCSDM > 2.0.CO;2.

Lau, K.-M., G. J. Yang, and S. H. Shen, 1988: Seasonal and intraseasonal climatology of summer monsoon rainfall over East Asia. Mon. Wea. Rev., 116, 18-37, https://doi.org/10.1175/ 1520-0493(1988)116<0018:SAICOS>2.0.CO;2.

_, M. K. Kim, and K. M. Kim, 2006: Asian summer monsoon anomalies induced by aerosol direct forcing: The role of the Tibetan Plateau. Climate Dyn., 26, 855-864, https://doi.org/ 10.1007/s00382-006-0114-z.

Lau, N., and M. J. Nath, 2000: Impact of ENSO on the variability of the Asian-Australian monsoons as simulated in GCM experiments. J. Climate, 13, 4287-4309, https://doi.org/10.1175/ 1520-0442(2000)013<4287:IOEOTV>2.0.CO;2.

Lee, D., L. Oreopoulos, G. J. Huffman, W. B. Rossow, and I. Kang, 2013: The precipitation characteristics of ISCCP tropical weather states. J. Climate, 26, 772-788, https://doi.org/10.1175/ JCLI-D-11-00718.1.

Li, J. D., Y. Liu, and G. Wu, 2009: Cloud radiative forcing in Asian monsoon region simulated by IPCC AR4 AMIP models. $A d v$. Atmos. Sci., 26, 923-939, https://doi.org/10.1007/s00376-0098111-x.

_ W. W. Wang, X. Dong, and J. Mao, 2017: Cloud-radiationprecipitation associations over the Asian monsoon region: An observational analysis. Climate Dyn., 49, 3237-3255, https:// doi.org/10.1007/s00382-016-3509-5.

- W. Wang, J. Mao, Z. Wang, G. Zeng, and G. Chen, 2019: Persistent spring cloud shortwave radiative effect and the associated circulations over southeastern China. J. Climate, 32, 3069-3087, https://doi.org/10.1175/JCLI-D-18-0385.1.

— Q. L. You, and B. He, 2020: Distinctive spring shortwave cloud radiative effect and its inter-annual variation over southeastern China. Atmos. Sci. Lett., 21, e970, https://doi.org/ 10.1002/asl.970.

Li, P., K. Furtado, T. Zhou, H. Chen, J. Li, Z. Guo, and C. Xiao, 2020: The diurnal cycle of East Asian summer monsoon precipitation simulated by the Met Office Unified Model at convection-permitting scales. Climate Dyn., 55, 131-151, https:// doi.org/10.1007/s00382-018-4368-z.

Li, Y., and H. Gu, 2006: Relationship between middle stratiform clouds and large scale circulation over eastern China. Geophys. Res. Lett., 33, L09706, https://doi.org/10.1029/2005GL025615.

—, R. Yu, Y. Xu, and X. Zhang, 2004: Spatial distribution and seasonal variation of cloud over China based on ISCCP data and surface observations. J. Meteor. Soc. Japan, 82, 761-773, https://doi.org/10.2151/jmsj.2004.761.

Li, Z., and Coauthors, 2016: Aerosol and monsoon climate interactions over Asia. Rev. Geophys., 54, 866-929, https://doi.org/ 10.1002/2015RG000500.

— aerosols and their impact on regional clouds, precipitation, and climate (EAST-AIRCPC). J. Geophys. Res. Atmos., 124, 13 026-13 054, https://doi.org/10.1029/2019JD030758.

Luo, Y., R. Zhang, and H. Wang, 2009: Comparing occurrences and vertical structures of hydrometeors between eastern China and the Indian monsoon region using CloudSat/CALIPSO data. J. Climate, 22, 1052-1064, https://doi.org/10.1175/2008JCLI2606.1.

Luo, Z. J., R. C. Anderson, W. B. Rossow, and H. Takahashi, 2017: Tropical cloud and precipitation regimes as seen from nearsimultaneous TRMM, CloudSat, and CALIPSO observations and comparison with ISCCP. J. Geophys. Res. Atmos., 122, 5988-6003, https://doi.org/10.1002/2017JD026569.

Marchand, R., T. Ackerman, M. Smyth, and W. B. Rossow, 2010: A review of cloud top height and optical depth histograms from MISR, ISCCP, and MODIS. J. Geophys. Res., 115, D16206, https://doi.org/10.1029/2009JD013422.

Matsumoto, J., 1997: Seasonal transition of summer rainy season over Indochina and adjacent monsoon region. $A d v$. Atmos. Sci., 14, 231-245, https://doi.org/10.1007/s00376997-0022-0.

Mekonnen, A., and W. B. Rossow, 2011: The interaction between deep convection and easterly waves over tropical North Africa: A weather state perspective. J. Climate, 24, 4276-4294, https:// doi.org/10.1175/2011JCLI3900.1.

Mooley, D. A., and B. Parthasarathy, 1984: Fluctuations in allIndia summer monsoon rainfall during 1871-1978. Climatic Change, 6, 287-301, https://doi.org/10.1007/BF00142477.

Ohsawa, T., H. Ueda, T. Hayashi, A. Watanabe, and J. Matsumoto, 2001: Diurnal variations of convective activity and rainfall in tropical Asia. J. Meteor. Soc. Japan, 79, 333-352, https://doi.org/ 10.2151/jmsj.79.333.

Oreopoulos, L., and W. B. Rossow, 2011: The cloud radiative effects of International Satellite Cloud Climatology Project weather states. J. Geophys. Res., 116, D12202, https://doi.org/ 10.1029/2010JD015472.

Qin, Y., Z. Chen, Y. Shen, S. Zhang, and R. Shi, 2014: Evaluation of satellite rainfall estimates over the Chinese mainland. Remote Sens., 6, 11 649-11672, https://doi.org/10.3390/rs61111649.

Radhakrishna, B., T. N. Rao, and K. Saikranthi, 2019: Spatial coherence of water vapor and rainfall over the Indian subcontinent during different monsoon seasons. J. Hydrometeor., 20, 45-58, https://doi.org/10.1175/JHM-D-18-0069.1.

Rana, S., J. McGregor, and J. Renwick, 2015: Precipitation seasonality over the Indian subcontinent: An evaluation of gauge, reanalyses, and satellite retrievals. J. Hydrometeor., 16, 631651, https://doi.org/10.1175/JHM-D-14-0106.1.

Romatschke, U., S. Medina, and R. A. Houze, 2010: Regional, seasonal, and diurnal variations of extreme convection in the South Asian region. J. Climate, 23, 419-439, https://doi.org/ 10.1175/2009JCLI3140.1.

Rossow, W. B., G. Tselioudis, A. Polak, and C. Jakob, 2005: Tropical climate described as a distribution of weather states indicated by distinct mesoscale cloud property mixtures. Geophys. Res. Lett., 32, L21812, https://doi.org/10.1029/2005GL024584.

- A. Mekonnen, C. Pearl, and W. Goncalves, 2013: Tropical precipitation extremes. J. Climate, 26, 1457-1466, https://doi.org/ 10.1175/JCLI-D-11-00725.1.

Sabin, T. P., and O. M. Pauluis, 2020: The South Asian monsoon circulation in moist isentropic coordinates. J. Climate, 33, 52535270, https://doi.org/10.1175/JCLI-D-19-0637.1.

Sahai, A. K., M. K. Soman, and V. Satyan, 2000: All India summer monsoon rainfall prediction using an artificial neural network. Climate Dyn., 16, 291-302, https://doi.org/10.1007/ s003820050328. 
Sahany, S., V. Venugopal, and R. S. Nanjundiah, 2010: Diurnalscale signatures of monsoon rainfall over the Indian region from TRMM satellite observations. J. Geophys. Res., 115, D02103, https://doi.org/10.1029/2009JD012644.

Sen Roy, S., and R. C. Balling, 2007: Diurnal variations in summer season precipitation in India. Int. J. Climatol., 27, 969-976, https://doi.org/10.1002/joc.1458.

Stachnik, J. P., C. Schumacher, and P. E. Ciesielski, 2013: Total heating characteristics of the ISCCP tropical and subtropical cloud regimes. J. Climate, 26, 7097-7116, https://doi.org/10.1175/ JCLI-D-12-00673.1.

Stephens, G. L., 2005: Cloud feedback in the climate system: A critical review. J. Climate, 18, 237-273, https://doi.org/10.1175/ JCLI-3243.1.

Su, Y., C. Zhao, Y. Wang, and Z. Ma, 2020: Spatiotemporal variations of precipitation in China using surface gauge observations from 1961 to 2016. Atmosphere, 11, 303, https://doi.org/ 10.3390/atmos11030303.

Sun, B., Y. Zhu, and H. Wang, 2011: The recent interdecadal and interannual variation of water vapor transport over eastern China. Adv. Atmos. Sci., 28, 1039-1048, https://doi.org/10.1007/ s00376-010-0093-1.

Tan, J., and C. Jakob, 2013: A three-hourly dataset of the state of tropical convection based on cloud regimes. Geophys. Res. Lett., 40, 1415-1419, https://doi.org/10.1002/grl.50294.

,-- , and T. P. Lane, 2013: On the identification of the largescale properties of tropical convection using cloud regimes. J. Climate, 26, 6618-6632, https://doi.org/10.1175/JCLI-D-1200624.1.

- — - W. Rossow, and G. Tselioudis, 2015: Increases in tropical rainfall driven by changes in frequency of organized deep convection. Nature, 519, 451-454, https://doi.org/10.1038/ nature14339.

Tian, S. F., and T. Yasunari, 1992: Time and space structure of interannual variations in summer rainfall over China. J. Meteor. Soc. Japan, 70, 585-596, https://doi.org/10.2151/jmsj1965.70.1B_ 585.

—_, and —_, 1998: Climatological aspects and mechanism of spring persistent rains over central China. J. Meteor. Soc. Japan, 76, 57-71, https://doi.org/10.2151/jmsj1965.76.1_57.

Tromeur, E., and W. B. Rossow, 2010: Interaction of tropical deep convection with the large-scale circulation in the MJO. J. Climate, 23, 1837-1853, https://doi.org/10.1175/2009JCLI3240.1.

Tselioudis, G., and W. B. Rossow, 2011: Time scales of variability of the tropical atmosphere derived from cloud-defined weather states. J. Climate, 24, 602-608, https://doi.org/10.1175/ 2010JCLI3574.1.

Wang, B., and LinHo, 2002: Rainy season of the Asian-Pacific summer monsoon. J. Climate, 15, 386-398, https://doi.org/10.1175/ 1520-0442(2002)015<0386:RSOTAP $>2.0$.CO;2.

- R. Wu, and K.-M. Lau, 2001: Interannual variability of Asian summer monsoon: Contrast between the Indian and the western North Pacific-East Asian monsoons. J. Climate, 14, 4073-4090, https://doi.org/10.1175/1520-0442(2001)014<4073: IVOTAS $>2.0 . \mathrm{CO} ; 2$

Wang, H., F. B. Sun, and W. B. Liu, 2018: The dependence of daily and hourly precipitation extremes on temperature and atmospheric humidity over China. J. Climate, 31, 8931-8944, https:// doi.org/10.1175/JCLI-D-18-0050.1.
Wang, Y., and C. Wang, 2016: Features of clouds and convection during the pre- and post-onset periods of the Asian summer monsoon. Theor. Appl. Climatol., 123, 551-564, https://doi.org/ 10.1007/s00704-015-1372-7.

Worku, L. Y., A. Mekonnen, and C. J. Schreck, 2019: Diurnal cycle of rainfall and convection over the Maritime Continent using TRMM and ISCCP. Int. J. Climatol., 39, 5191-5200, https:// doi.org/10.1002/joc.6121.

- — , and — 2020: The impact of MJO, Kelvin, and equatorial Rossby waves on the diurnal cycle over the Maritime continent. Atmosphere, 11, 711, https://doi.org/10.3390/atmos11070711.

Xie, S., H. Xu, N. H. Saji, Y. Wang, and W. T. Liu, 2006: Role of narrow mountains in large-scale organization of Asian monsoon convection. J. Climate, 19, 3420-3429, https://doi.org/ 10.1175/JCLI3777.1.

Xue, M., X. Luo, K. Zhu, Z. Sun, and J. Fei, 2018: The controlling role of boundary layer inertial oscillations in meiyu frontal precipitation and its diurnal cycles over China. J. Geophys. Res. Atmos., 123, 5090-5115, https://doi.org/10.1029/2018JD028368.

Yang, Y., C. Zhao, and H. Fan, 2020: Spatiotemporal distributions of cloud properties over China based on Himawari-8 advanced Himawari imager data. Atmos. Res., 240, 104927, https://doi.org/ 10.1016/j.atmosres.2020.104927.

Yi, L., 1995: Characteristics of the mean water vapor transport over monsoon Asia. Adv. Atmos. Sci., 12, 195-206, https://doi.org/ 10.1007/BF02656832.

Yu, R. C., Y. Q. Yu, and M. H. Zhang, 2001: Comparing cloud radiative properties between the eastern China and the Indian monsoon region. Adv. Atmos. Sci., 18, 1090-1102, https:// doi.org/10.1007/s00376-001-0025-1.

— T. Thou, A. Xiong, Y. Zhu, and J. Li, 2007: Diurnal variations of summer precipitation over contiguous China. Geophys. Res. Lett., 34, L01704, https://doi.org/10.1029/2006GL028129.

Zelinka, M. D., and D. L. Hartmann, 2009: Response of humidity and clouds to tropical deep convection. J. Climate, 22, 23892404, https://doi.org/10.1175/2008JCLI2452.1.

Zhang, R., A. Sumi, and M. Kimoto, 1996: Impact of El Niño on the East Asian monsoon: A diagnostic study of the '86/87 and '91/ 92 events. J. Meteor. Soc. Japan, 74, 49-62, https://doi.org/ 10.2151/jmsj1965.74.1_49.

Zhang, Y. H., M. Xue, K. Zhu, and B. Zhou, 2019: What is the main cause of diurnal variation and nocturnal peak of summer precipitation in Sichuan Basin, China? The key role of boundary layer low-level jet inertial oscillations. J. Geophys. Res. Atmos., 124, 2643-2664, https://doi.org/10.1029/2018JD029834.

Zhao, C. F., Y. Y. Chen, J. M. Li, H. S. Letu, Y. F. Su, T. M. Chen, and X. L. Wu, 2019: Fifteen-year statistical analysis of cloud characteristics over China using Terra and Aqua Moderate Resolution Imaging Spectroradiometer observations. Int. J. Climatol., 39, 2612-2629, https://doi.org/10.1002/joc.5975. , and Coauthors, 2020: Aerosol characteristics and impacts on weather and climate over Tibetan Plateau. Natl. Sci. Rev., 7, 492-495, https://doi.org/10.1093/nsr/nwz184.

Zhou, S., J. Yang, W. C. Wang, C. Zhao, D. Gong, and P. Shi, 2020: An observational study of the effects of aerosols on diurnal variation of heavy rainfall and associated clouds over BeijingTianjin-Hebei. Atmos. Chem. Phys., 20, 5211-5229, https:// doi.org/10.5194/acp-20-5211-2020. 
